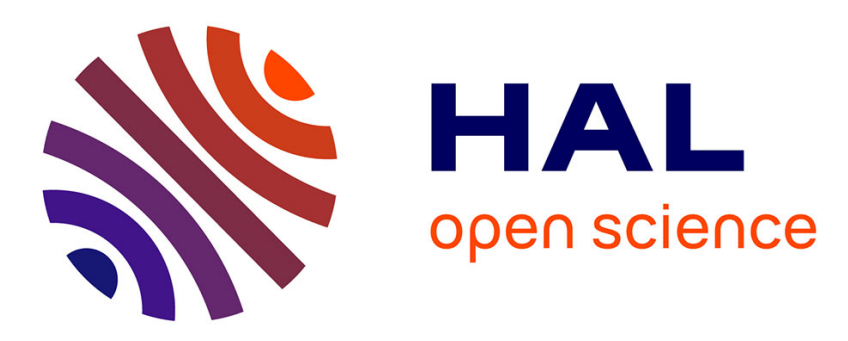

\title{
Observations from radical innovation projects considering the company context
}

Bernard Yannou, Marija Jankovic, Yann Leroy, Gül E. Okudan Kremer

\section{To cite this version:}

Bernard Yannou, Marija Jankovic, Yann Leroy, Gül E. Okudan Kremer. Observations from radical innovation projects considering the company context. Journal of Mechanical Design, 2013, 135 (2), pp.1-21. 10.1115/1.4023150 . hal-01152298

\section{HAL Id: hal-01152298 \\ https://hal-centralesupelec.archives-ouvertes.fr/hal-01152298}

Submitted on 15 May 2015

HAL is a multi-disciplinary open access archive for the deposit and dissemination of scientific research documents, whether they are published or not. The documents may come from teaching and research institutions in France or abroad, or from public or private research centers.
L'archive ouverte pluridisciplinaire HAL, est destinée au dépôt et à la diffusion de documents scientifiques de niveau recherche, publiés ou non, émanant des établissements d'enseignement et de recherche français ou étrangers, des laboratoires publics ou privés. 
Yannou, B., Jankovic, M., Leroy, Y., and Okudan Kremer, G. E., 2013, "Observations from radical innovation projects considering the company context," Journal of Mechanical Design, 135(2), DOI: 10.1115/1111.4023150.

\section{OBSERVATIONS FROM RADICAL INNOVATION PROJECTS CONSIDERING THE COMPANY CONTEXT}

\author{
Bernard Yannou \\ Professor \\ Laboratoire Genie Industriel \\ Ecole Centrale Paris \\ 92290 Chatenay-Malabry, France \\ bernard.yannou@ecp.fr \\ Yann Leroy \\ Assistant Professor \\ Laboratoire Genie Industriel \\ Ecole Centrale Paris \\ 92290 Chatenay-Malabry, France \\ yann.leroy@ecp.fr
}

\author{
Marija Jankovic \\ Assistant Professor \\ Laboratoire Genie Industriel \\ Ecole Centrale Paris \\ 92290 Chatenay-Malabry, France \\ marija.jankovic@ecp.fr \\ Gül E. Okudan Kremer \\ Associate Professor \\ Penn State University \\ Harold and Inge Marcus Department of \\ Industrial and Manufacturing Engineering \\ 361 Leonhard Building \\ University Park, Pennsylvania 16802 USA \\ gkremer@psu.edu
}

\section{ABSTRACT}

The development of product-service innovation projects within the context of a company is not yet supported by clear theories and methodologies. Our objective is to analyze innovation and idea generation for such projects from the fuzzy front end to the selected design concept, assessing their potential to be successfully developed and launched on the market. We present a protocol study, using which data derived from 19 innovation projects of five types and conducted by 86 students are analyzed. Sixty-one variables are observed, thus generating 700 data vectors. Bayesian network learning is used to explore conditional inferences among these variables. We examine conditional probabilities between the innovation process means and the significant results produced for the company, modulated by the influence of contextual variables. A number of surprising findings are drawn about the link between problem setting and problem solving processes, the importance of certain contextual variables, and the potential discrepancies between the apparent and produced results of innovative projects. Conducted analyses imply the need for novel innovation evaluation frameworks.

\section{INTRODUCTION}

Shah et al. [1] noted that "A wide range of formal methods have been devised and used for idea generation in conceptual design. Experimental evidence is needed to support claims regarding the effectiveness of these methods in promoting idea generation in engineering design." Addressing this assertion, the engineering design community has investigated how design processes should progress to yield creative outcomes and has attempted to determine the main factors of creativity and innovation in design outcomes. However, most of these investigations have ignored the company centric contextual factors. Among the reasons for this are: (1) the existing design process models do not specifically consider the company context, and (2) most of the experiments have been conducted in classroom settings with little or no input from industry participants. In the present research, we undertake the challenge of integrating company centric contextual factors to an increased level of fidelity during investigations of methods intended to achieve innovation in design projects.

Radical Innovation Design (RID) is the basis for our design process model as it specifically considers contextual factors. RID evolved over years of innovation management experimentation in industry. It focuses primarily on those design stages from the initial need statement to the choice of the conceptual design solution, which is the design outcome determined to maximize value creation within a specified industrial context. Successive to design principles already in the literature, RID is based on a set of new principles and tools, organized around a design process using radical investigation of the highest value-creating design solutions.

Our study was initiated by an analysis showing that current design methodologies have a number of shortcomings when addressing a practical innovative product or service development process within a given company [2; 3]. 
Furthermore, evidence suggested that the result of the conceptual design stage is much more than the result of a random and creative process and requires a radical exploration of value creation opportunities within the company context (see [4]). While idea generation methods have been studied extensively, the quality of design outcomes has typically been assessed without consideration of the company context. Indeed, the quality criteria adopted have sometimes concerned more the means (number of generated ideas, intensity of conceptual design process) than the quality of the chosen conceptual design solution itself. In addition, previous research has lacked clarity concerning mechanisms to improve the design process or explain the reasons for variations in the value and quality of innovative project outcomes. Finally, we posit that an objective assessment of output quality is not possible, since assessment is essentially a subjective perception of expert jury members or steering committee members; this subjectivity in outcome value perception has not often been taken into account in analyses.

This work's objective is to experimentally assess the effective value creation of a selected design concept in the context of an expected radical innovation in a company ecosystem. This exploration is seen as the basis for developing further "a model of value creation with company context integration" including generation, evaluation and selection processes.

In section 2, we review the literature on conceptual design, design outcome quality and idea generation. Section 3 more formally presents the study objectives and terminology, followed in section 4 by the definitions of variables and the presentation of the experimental protocol. Section 5 provides the rationale for choosing the Bayesian Networks as the analysis method, along with implementation details. Section 6 presents three Bayesian Networks overlaid on major observed variables, namely, the quality of problem setting process, the quality of problem solving process and the organization of creativity. In section 7 a summary of these observations is provided. Finally, section 8 concludes with our contribution to innovation and idea management in the context of need-driven radical innovations of companies.

\section{LITERATURE REVIEW ON THE DIFFERENT CONCEPTUAL DESIGN PROCESSES AND THEIR RELATION TO DESIGN OUTCOMES AND INNOVATION}

It is widely accepted that the conceptual design process consists of the generation of concepts, the exploitation of these concepts, and their evaluation [5;6]. What is not clear, however, is how this process can be managed to assure intended outcomes, recently of more interest -- innovative concepts. The conceptual design process, in essence, is a cognitive process, which demands further exploration to identify criteria, indicators, measurement systems or prescribed processes leading to intended outcomes. Indeed, there are several research streams exploring this problem from different vantage points: prescribing and defining the design process and support tools in design exploration [7-9], identifying the design criteria which must be taken into account [10-12], defining and exploring the impact of creativity methods and ideation [13-16], identifying the indicators that can be used in order to predict level of innovation $[17 ; 18]$ and exploring the correlation between different deliverables and their outcomes [19-22]. We summarize the state of the art on these research streams below.

\subsection{What is the 'Ideal' organization of the conceptual design that guarantees an effective design exploration?}

The design exploration process is an important part of design creativity and novelty [23]. Design exploration is assumed to proceed in a divergent or convergent fashion $[7 ; 9$; 24]. Cross [7] asserted it to be mostly convergent but requiring a deliberate divergence in the search for novel ideas (see Fig. 1). Although Pugh's conceptual design model [9] also involves convergent and divergent thinking, progressing in an alternating way (see Fig. 2), he is a proponent of evaluating all generated concepts in a disciplined and continuous manner to gradually decrease the number of the solutions (see [8]).

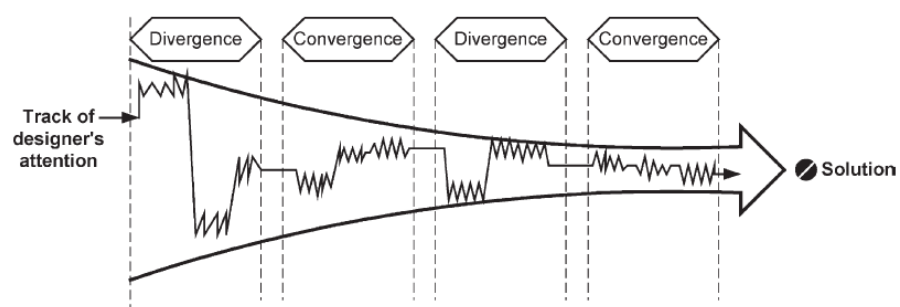

Fig. 1. The conceptual design process defined by Cross [7]

More recently, Liu et al. [8] (having adopted the progression through alternating convergence and divergence as the "ideal approach" to design) further defined how the continuous concept evaluation should proceed. In a representation of the ideal design process (see Fig. 3), concepts are evaluated through heuristics, position and motion screening. The development of the process is inspired by the definition of the "Balanced" search by Fricke [25]. Liu et al. [23] also developed the FuncSION tool to support the concept generation process. They argue that this approach increases the effectiveness of the design exploration without diminishing the width of the design space explored.

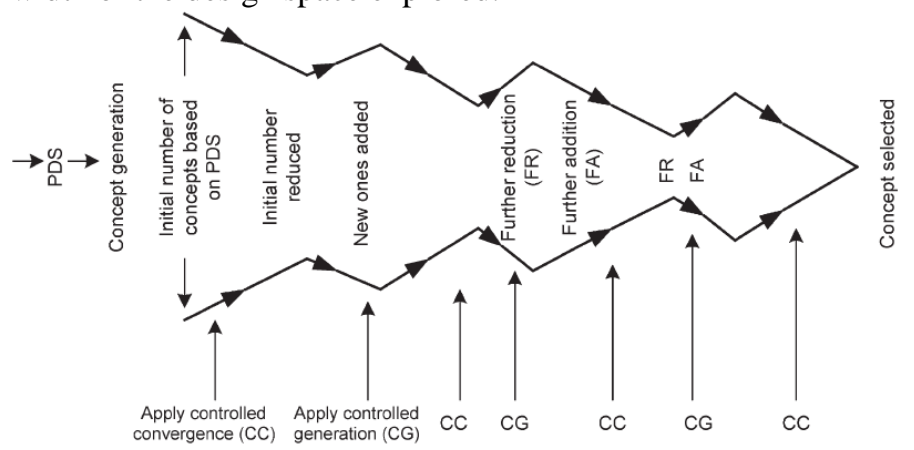

Fig. 2. Pugh's conceptual design process [9] 


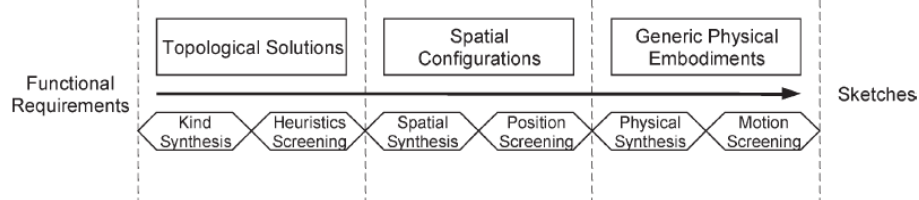

Fig. 3. Liu, Chakrabarti and Bligh's proposition of an 'ideal' design process and design support tool [8]

The relation between effective design space exploration and creativity is not clear, however. For example, Sarkar and Chakrabarti [26] conducted a set of laboratory experiments on three design phases: 1) problem understanding, 2) idea generation and 3) evaluation and selection. Four types of searches were observed in their experiments: "unknown", "global", "local" and "detail." All were observed across the three design phases. Observations revealed a significant (and consistent across phases) correlation between the level of search at any one design phase and that of the following phase. However, the correlations between the level of search and creativity across phases were uneven: 0.67 between problem search and creativity, 0.85 between solution search and creativity, and 0.62 between evaluation search and creativity.

\subsection{How do different design stages and deliverables contribute to the successful realization of conceptual design?}

This research stream explores the potential impact of various deliverables (e.g., concept sketches, prototypes and design reports) on design outcomes. Sketching and sketches have received considerable attention in this regard. The art of sketching and sketches themselves are considered an important part of conceptual design, as well as the primary way for designers to condense (and represent) their knowledge and exploration $[27 ; 28 ; 21]$. Yang et al. [29; 22] focused on the impact of the quantity and timing of generated sketches on design outcomes. Their statistical analysis revealed that the quantity of concepts significantly correlated with project grades. Yang [21] also found that preliminary sketching and prototyping led to better project grades. Although informative, these experiments included only student projects and hence the results cannot be transferred directly to company or industrial project settings; thus, an extension of the above-cited work in such settings is needed.

Yang [20] also explored the influence on design outcomes of prototype complexity and quantity as well as the time spent on prototyping. Her experimental results, again involving student subjects, showed that the fewer the number of parts in a device, the greater the grade and design competition ranking. As with the sketching experiments, the experimental subject pool inhibits the direct applicability of the results to complex product/system designs in company contexts.

Through observations of 50 designers and detailed analyses of 13 individual design processes, Fricke [25] explored the relation between adopted design strategies and the quality or relevance of the design outcomes. The design strategies, considered as different design activities, derived from a descriptive model of individual design processes consisting of a general approach to solving complex problems, a strategic approach, a tactical approach, design actions and design routines. Among the conclusions concerning the relevance of various strategies to good design outcomes, Fricke stated that only those designers who saw the relative importance of the flexible-methodical approach and adapted it to the design problem were successful in reaching the optimal design.

Another deliverable studied for its relation to design outcome is the textual design documentation, or the design report $[19 ; 30 ; 31]$. For example, Dong et al. [19] suggested that a correlation exists between the semantic coherence of design reports and successful product team outcomes. However, teams with low performance were also found to create highly coherent reports.

\subsection{Developing idea generation methods and measuring their quality and effectiveness}

Another key area for research is the characterization and measurement of the quality or effectiveness of idea generation methods and how they relate to innovation. Two key research groups address this question: cognitive psychologists and design study theorists. Shah and Vargas-Hernandez [16] provided an overview of the research in this area and proposed a categorization of idea generation methods. Formal idea generation methods are broadly classified into two categories: intuitive and logical. Intuitive methods have five sub-categories [1]: Germinal, Transformational, Progressive, Organizational, and Hybrid. Logical methods may be classified into two subcategories: History-based and Analytical. Other surveys of idea generation methods can be found in $[32 ; 16 ; 33]$.

More closely related to the work presented in this paper, Chakrabarti [34] generated an extensive survey concerning different criteria that are essential for creative thinking. Based upon previous studies in this field (Rhodes 1961, Read 1951, Perkins 1988, Wallas 1926 cited in [35], Torrance 1979 cited in [36], [37], [38]), Chakrabarti proposed a global framework regrouping influencing factors on creativity (see Fig. 4). He identified three major factors (motivation, knowledge and flexibility) as well as the exploration of their interdependence, as crucial for creativity in design. 


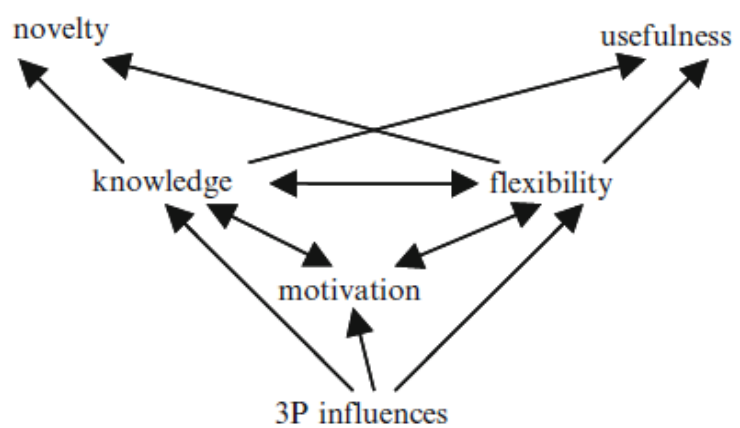

Fig. 4. Influencing factors on creativity [34]

Shah et al. [16] proposed four separate effectiveness measures: novelty, variety, quality and quantity. Novelty measures how unusual or unexpected an idea is as compared to other ideas. Variety is a size measure of the explored solution space. Quality is a measure of the feasibility of an idea and how close it comes to meeting design specifications. Quantity is the total number of ideas generated. While Shah et al. argued that due to aggregation, information loss can occur in an overall effectiveness measure and thus it will not benefit a design team, they also pointed out a real need for a unique indicator to support project comparison.

Sarkar and Chakrabarti [39] addressed methods for assessing innovation in such a way as to integrate the notion of development deadlines and degree of creativity - two factors they found missing in Shah's metrics. They also highlighted the need to define the degree of creativity of products where creativity is considered a function of novelty and usefulness. Their proposed methodology assesses novelty using the FBS (Function, Behavior, Structure) model to determine if the products are highly novel, and then implements the SAPPhIRE model to assess the degree of novelty relative to previous products. Usefulness is assessed using a weighted objective method measuring actual use across three parameters: 1) importance (effect per usage), 2) number of people using the product, and 3) period of use. The SAPPhIRE model, developed by Chakrabarti et al. [40] aims at proposing a framework for design to encourage novelty. It is a causal model which integrates physical laws with design principles. To enhance novelty, Srinivasan and Chakrabarti [41] propose to use Laws and Effects, Action, State Change, Parts Phenomenon, Input and Organ as elements that are related to and describe currently designed artifacts. This proposed framework still needs to be evaluated in the field.

Goldschmidt and Tatsa [42] used linkography to determine if and how selected "good" ideas are related to other ideas presented during the idea generation process. Linkography, developed by Goldschmidt [43; 44] and extended by others [45], is a system of notation and design process analysis that focuses on links among design moves, design ideas or decisions. Goldschmidt and Tatsa [42] did not find a significant correlation between quality (associated in that study with the final grade) and the number of ideas generated. However, a significant positive correlation was found between the number of what students evaluated as critical ideas, and quality. The study also showed a significant correlation between composite ideas (those addressing more than three topics) and the quality of work. The increase in links amongst the ideas had a significant impact on the final result. The authors related this result to the idea that designers are said to be 'synthesizers' of ideas and suggested that the links and the density are indicative of the quality and creativity of the process.

There are also studies on the conditions necessary for successful projects [18] and on eliciting the influence of the sketching activity in terms of quantity, quality and relationships between ideas. However, our review of the literature did not locate studies on relating the different stages and tools adopted along the design process to more sophisticated measures of (conceptual design) outcomes in real company contexts. It is this gap which our work addresses.

\subsection{Identifying the favorable conditions to innovate}

Design scholars consider design concepts to be successful if they are innovative or if they provide a competitive advantage in the market. The early design stages are characterized by information uncertainty. It is, therefore, difficult to accurately predict which concepts or ideas have the potential for innovation. Astebro [17] explores the impact of 36 innovation, technology and market characteristics on the probability of success in the early design stages. He suggests a forecast for use as a screening tool of early design reviews in which the key success factors aim at examining the likelihood of projects reaching the market. In his study, three criteria address potential "technological improvement of the invention," five address "technological opportunity," three address "potential external constraints," seven address "measures of demand," five address "innovation characteristics," one concerns the price, three address "cost measures," and the balance addresses appropriate conditions and various investment criteria.

Millier [18] addresses the issue of necessary conditions or key factors that lead to successful innovation projects. These key factors, based on the consideration of different risks linked to failure, are defined as 1) technical, 2) economic or commercial, and 3) internal/organizational conditions. Technical factors consist of product unicity, intellectual property issues, scientific or technological "momentum" and industrial scalability. Economic factors concern the existence of a market and the identification of market segments and clients which have already made the need explicit, and foresight on regulations, law or other obstacles. Internal or organizational conditions concern ensuring the internal promotion of the project, project organization and planning, development of the alliances and the distribution networks, and identification of different resources within the company. Millier suggests this model can also be applied as a managerial model for project evaluation. 
Clearly, the two approaches from the marketing and strategic product innovation management fields tackle the innovation issue differently than that from traditional design engineering. They consider the ultimate goal is the likelihood of success in the market instead of just "being creative." We posit, then, that one could be positively inspired by this type of ultimate goal measure. Further, these works consider the adequacy of a conceptual solution within the company ecosystem along with an extensive set of influencing criteria, instead of a more limited view of quality and intensity of the creative process. In the context of a company, one can consider that the design process is fairly stable (due to established behaviors, tools and procedures) but that it is possible to overlook various technological or market opportunities. Therefore, we argue that the consideration of different types of contextual factors which define a company's ecosystem and their relation to different design processes as well as design outcomes appears to be a critical gap in the design engineering literature.

\section{STUDY OBJECTIVES}

Drawing on our review of the relevant literature, we assert that although various deliverables, tools and processes of design have been studied for their impact on design outcomes, including creativity and innovation, previous studies by and large have considered only a small set of potential variables and hence are not comprehensive in their analysis. Moreover, much of the empirical experimentation has occurred in classroom settings, taking into account neither how non-student designers would perform nor contextual factors that impact the design process in company settings. Accordingly, in an effort to more comprehensively study the design process factors (including context) leading to innovation, we propose an experimental protocol. The intent of the experiment analyzed in this paper is to assess whether design methods and deliverables recommended in the adopted design process, Radical Innovation Design (RID), influence the perceived value of the selected design concepts.

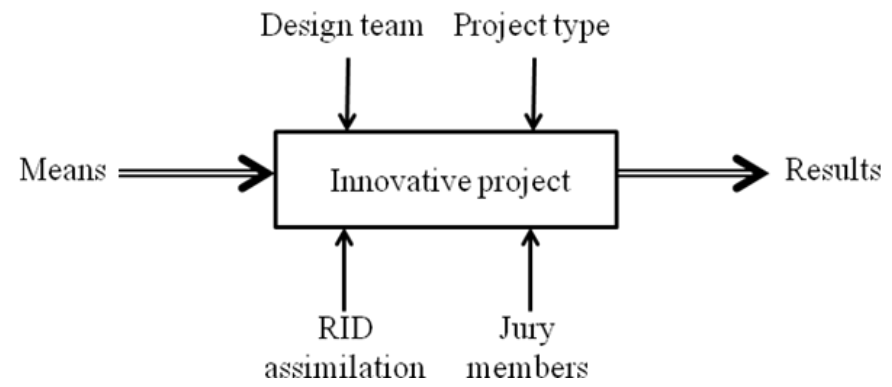

Fig. 5. Our observation protocol of innovative projects

Fig. 5 shows the key elements of the experimental protocol. We refer to the design methods and deliverables as means of the problem setting and the problem solving processes. The value of the selected design concept (comprising part of the results) is evaluated by expert jury members, half of whom are company executives. The evaluation is completed with the consideration of the expected value creation in the company ecosystem-not only the apparent innovativeness of the idea or concept. The evaluation of results (the value created for the company) is made independently of the means employed by a combination of faculty and company R\&D managers.

An additional objective of this analysis is to identify key factors and conditional dependencies among phenomena design acts and value results - concerning innovation management in the context of design team features, project type features and the degree of adoption of innovation principles and tools by the project participants (here, adoption of RID methodology).

Research questions we sought to answer are as follows:

1) What are the factors influencing the quality of the problem setting?

2) What are the relationships between problem setting efforts and the overall quality of the problem solving process?

3) What relations exist between a) the qualities of the problem setting and the problem solving process, and $b$ ) the resulting quality or value of the innovative project outcome?

In addition, we addressed the following issues:

4) Do we need flexibility in design processes? Are certain design means or design results more appropriate to certain project types?

5) How confident can we be about design means and design results? Are the evaluations made by the jury really objective, or are they highly dependent on jury member selection?

\section{EXPERIMENTAL SETTING AND VARIABLES}

Details about the experimental setting and the variables are provided below. As noted above, RID was selected as the main design methodology; we provide information on its principles as well.

\subsection{Radical Innovation Design}

Radical Innovation Design (RID) methodology can be used when a company's objective is to innovate fundamentally. It requires taking into account the company's position in an ecosystem, i.e. its market presence and brand reputation, its existing product-service-technology portfolio, competitors and suppliers, and its financial, industrial and intellectual assets (including innovation know-how, technical competences, and patent portfolio). With regard to this company context (rarely considered as an input to an innovation process), the goal of RID is to innovate as much as possible, creating positive differentiation in the market and changing the conventional rules of competition. In its essence, RID is a systematic exploration/exploitation process which progresses through four stages.

1) Exploration of value creation opportunities around the initial idea or statement. The initial idea/statement is systematically redefined in a more legitimate ideal need. 
Within this new exploration perimeter, existing usages, needs and product experiences are populated, investigated and benchmarked so as to yield input for stage \#2.

2) Definition of a promising and coherent perimeter of ambition which is a subset of the aforementioned ideal need. This perimeter of ambition must represent an opportunistic potential of value creation in the context of the company ecosystem.

3) Definition of value promising product-service scenarios, a.k.a. briefs, starting from the perimeter of ambition. These briefs must be qualified (often by storyboards) and quantified (market size and consumers' willingness-topay).

4) For each brief studied, a systematic listing of value tracks and value drivers, a.k.a. innovation leads (see the use of RID methodology in the context of EADS company [46; 47]) are performed. Each innovation lead is then investigated in the form of a systematic creativity workshop. Findings are combined into consistent design concepts which are subsequently sketched or prototyped and assessed.

The RID methodology is organized following Herbert Simon's approach around a two-part macro-process: the problem setting macro-stage and the problem solving macrostage. Fig. 6 represents these two macro-stages within the RID innovation wheel. Of the four radical exploration/exploitation stages identified above, the first two belong to the problem setting macro-stage, and the two last belong to the problem solving macro-stage. The RID innovation wheel spans transition from the initial idea or statement to the feasibility and innovation dossier, passing through intermediate results including ideal need, perimeter of ambition, brief(s), and concepts. In practice, a series of micro-stages are defined and documented with expected intermediate results and reports, practical examples for inspiration and a toolbox. These microstages and tools are not detailed here but are provided in Table 1 as design means variable series.

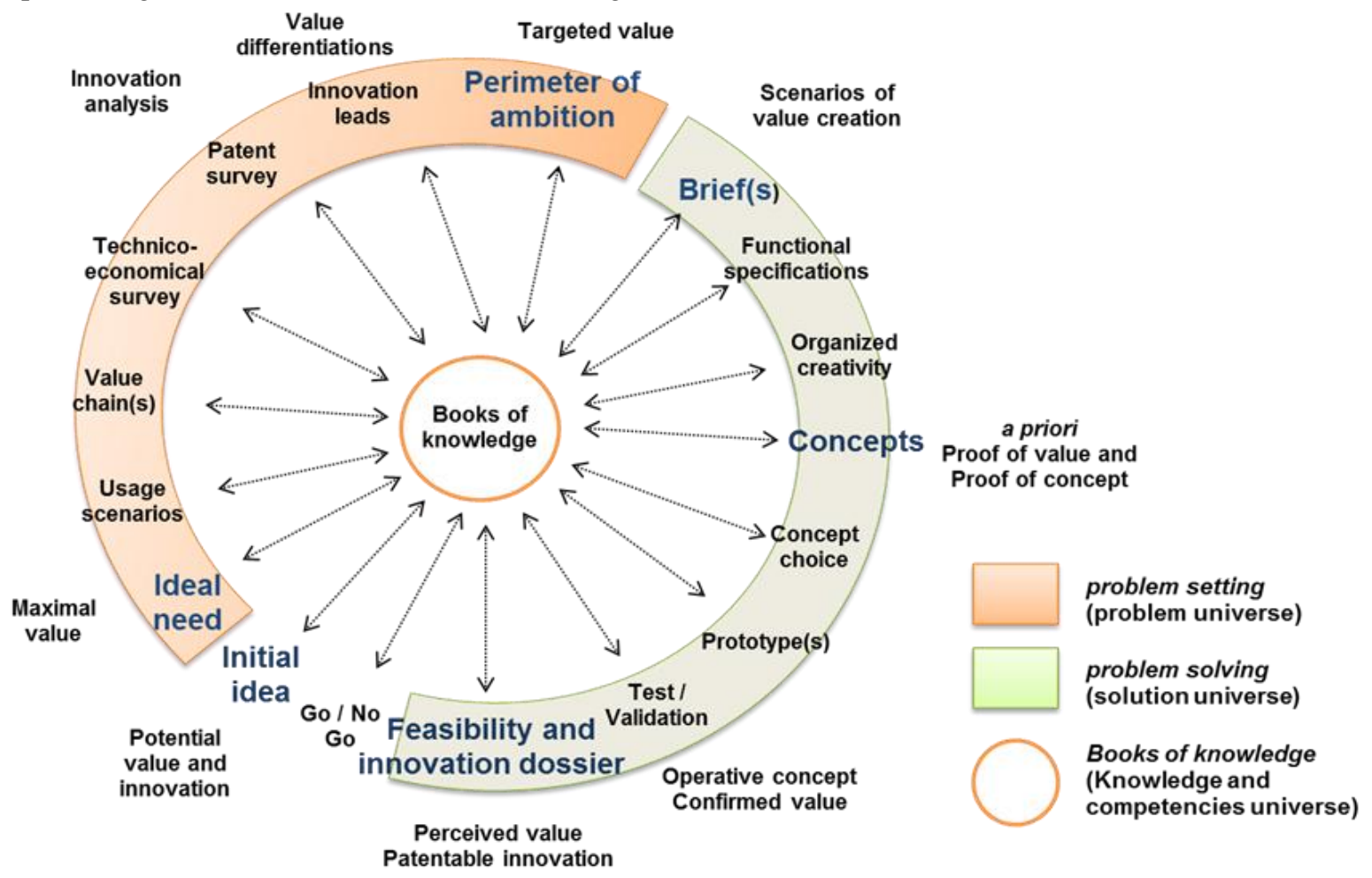

Fig. 6. The RID innovation wheel: From initial idea to feasibility and innovation dossier... through ideal need, perimeter of ambition, brief(s), concepts 


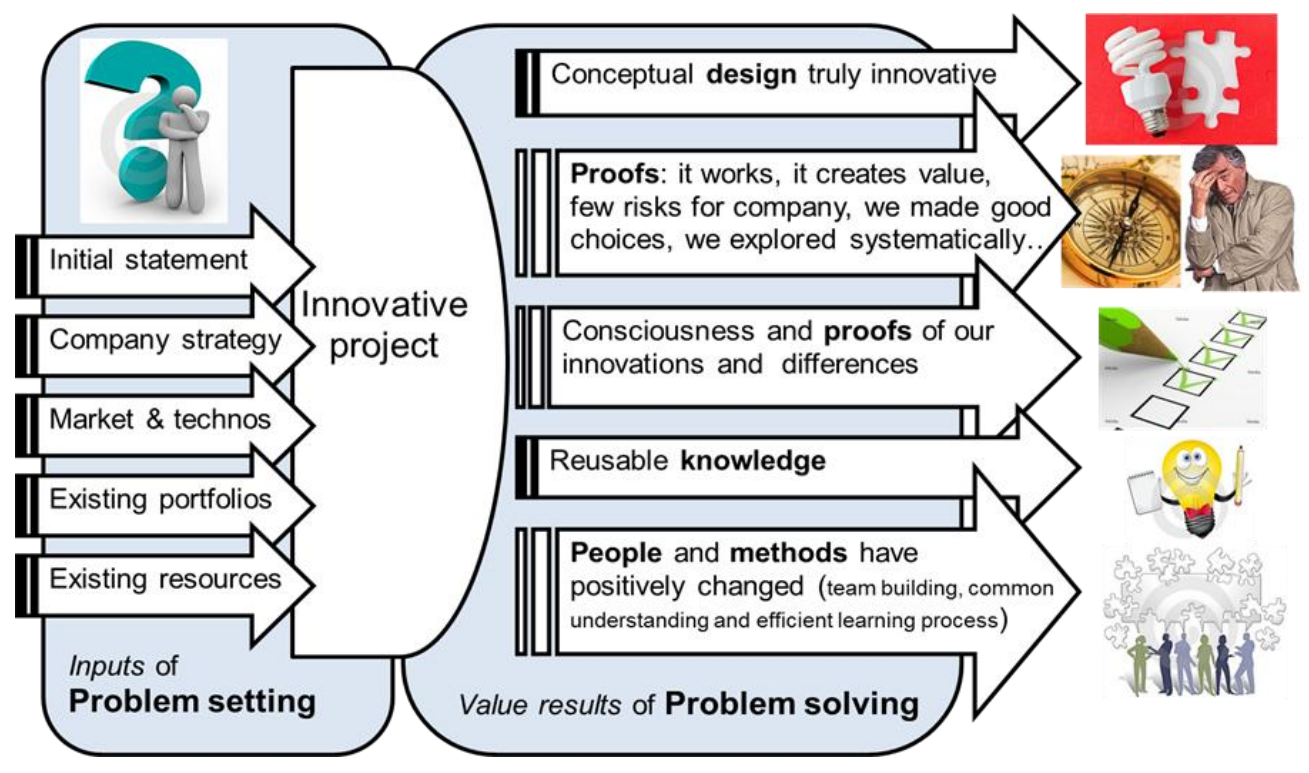

Fig. 7. The value machine of an innovative project using RID methodology

A determining concept of RID is the consideration of the conceptual design stage as an investigation process. Investigation is understood as exploring all potential leads and then refining and evaluating conceptual designs that appear to be potential value makers. This investigation is supported by three types of proofs that are built and reinforced throughout the process:

- the proofs of concept for bringing evidence that "it works or it is likely to work in situations the service is expected to be delivered";

- the proofs of value for bringing evidence that "it is differentiating from the existing solutions in terms of service utility as well as new satisfied needs, on large and credit-worthy market segments"; and

- the proofs of innovation for bringing evidence that "the invention may be protected and the innovation may be communicated, perceived, understood and valued, i.e. it corresponds to a certain willingness-to-pay".

Fig. 7 summarizes all the value results that may be expected at the end of an innovative design project based on an RID vantage point. This transformation between input data (the initial idea and the company and project ecosystem) and project value results is called the RID value machine.

\subsection{Experimental setting and projects}

A total of 86 students enrolled in "Design and Innovation of Products and Services" (SE2200) course participated as subjects during data collection. Eleven 3-hour sessions were conducted during Fall 2009. Lectures were given about the RID process and its macro- and micro-stages along with corresponding methods and tools. Learning in the course was demonstrated through projects, assigned to teams of 4 or 5 students.
Five project subjects (initial design statements) were presented in the initial course session, represented by two established companies, one start-up group and two NonGovernmental Organizations. These projects were as follows:

1. Plastic bag facilitator (practical, sustainable, reliable way to move purchased goods)

2. Innovative carpool system/service (with no required registration and reduced waiting times)

3. CD-ROM storage in different conditions of use

4. Weighing machine adapted to African children (for healthcare follow-up of 0-5 year old children; see a conceptual solution in Fig. 8)

5. Non wood-based African stove (to save forests)

In discussions during the course, the students generated many ideas. To put these into practice, they were required to select the best idea taking into account the company or NGO context for which they were designing. Only the best concept put forth by students was evaluated for its value.
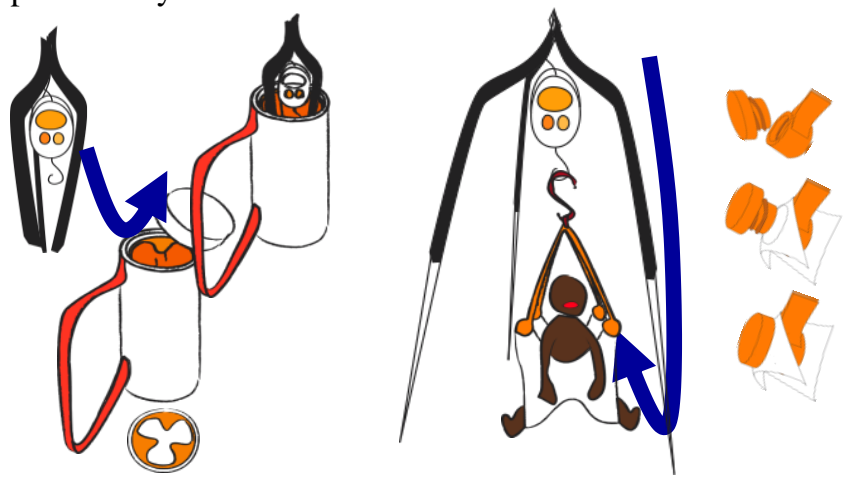

Fig. 8. Tripod concept for weighting machine for African children

A total of 19 project teams were established (4 different teams on 4 projects and 3 teams for the last project). Teams were formed by the course instructors to ensure a distribution of 
gender, nationality, and educational backgrounds by utilizing student on-line profiles. During the first lecture session, each team had 20 minutes to identify two projects they did not want to work on. This procedure was used to simulate a design team at a company setting, addressing these purposes: (1) to allow a certain freedom of choice and prevent de-motivation from the beginning; (2) to simulate a professional situation in which an engineer voluntarily enters a company, but where the precise subject of a project is assigned by others; and (3) to initiate negotiating and compromising within the newly formed design team.

Course instructors served as design process experts as well as project resource facilitators, although they did not contribute to project management. The two-month timeframe consisted of RID training and an intense project period. On average, students did not invest more than 50 extra hours of research, in addition to the 33-hour course (including 16 hours of project tutorials). As per the judgments of the company representatives, the results were very satisfactory.

\subsection{Variables and data collection}

Strict document management and examination procedures were applied to support the intended rigorous analysis. During the project, the students were asked to upload their Intermediary Design Objects (IDOs) in dedicated sub-directories of a partitioned collaborative platform; these IDOs included written reports as well as other design representations. Through these IDOs, data for 21 design means were collected; these design means variables are provided in Table 1.

Table 1. Design means variables

\begin{tabular}{l|l}
\hline Var. & Description \\
\hline D1 & Proper redefinition of ideal need \\
D2 & Definition of stakeholders \\
D3 & Definition of present usage contexts \\
D4 & Initial inventory of knowledge and competence needs \\
D5 & Production of books of knowledge \\
D6 & Project management of problem setting period \\
D7 & Clear definition of justified brief(s) \\
D8 & Listing of innovation leads (expectations, \\
& dysfunctions, and differentiations) \\
D9 & Organization of creativity (brainstorming workshops \\
& from innovation leads) \\
D10 & Concept generation by consistent combinations of \\
& ideas \\
D11 & Explicit investigation/refinement process of \\
& conceptual pathways \\
D12 & Perceptual assessments of concepts (semantic \\
& differential profiles) \\
D13 & Functional analysis \\
D14 & Concept sketching \\
D15 & Detailed concept \\
D16 & Eco-Design \\
D17 & Development of associated services and business \\
\hline
\end{tabular}

\begin{tabular}{l|l}
\hline D18 & models \\
D19 & $\begin{array}{l}\text { Fetailed usage analysis of chosen concept } \\
\text { commercializing, patenting, etc. })\end{array}$ \\
\hline \multicolumn{2}{c}{ Aggregate variables (summations) } \\
\hline D20 & $\begin{array}{l}\text { (D20=D1:D6) Overall quality of problem setting } \\
\text { process } \\
\text { D21 }\end{array}$ \\
\hline
\end{tabular}

The jury consisted of 8 members (the educational team), of whom 4 were highly experienced in design innovation (2 Associate/Full Professors and 2 company Innovation Directors) and 4 were confirmed ( $2 \mathrm{PhD}$ students in design engineering who were familiar with RID methodology and 2 company engineers who were not especially dedicated to innovation activities). The jury members were not allowed to scrutinize the collaborative platform directories before the final oral defense occurred. The objective was to set the evaluation context as it would be in a company environment, i.e. by experienced people asking for proof to validate a conceptual choice in order to engage further investment. This evaluation was limited to a 15minute presentation, followed by a 15-minute Q/A session, presented to the students as such: "As if we were in front of the steering committee of a design department at a go/no-go step." Students were informed that the jury would assess not only the value of the technical result but also the design result values noted in Fig. 2-in particular, the proofs of concept, value and the traceability of the design process ("Could we do better?"). Appropriately, this final oral exam was called the "Prove It" seminar.

Two juries were formed, each composed of two experienced and two confirmed members, charged with examining, respectively, 9 and 10 projects. During the presentations, the jury members assessed 13 design results variables (shown in Table 2) for each defended project. Each student was asked to complete an anonymous questionnaire to document:

- the design team features across 10 variables such as team atmosphere, extra time dedicated to the project, or personal satisfaction (shown in Table 3);

- the degree of adoption of innovation principles and tools of RID methodology according to 8 variables (shown in Table 4).

Table 2. Design Results Variables

\begin{tabular}{l|l} 
1) & $\begin{array}{l}\text { The final result is innovative, mature and sufficiently } \\
\text { validated }\end{array}$ \\
\hline R1 & Final perception of the chosen concept by the jury \\
R2 & Convincing proof of value creation \\
R3 & Well adapted perimeter of ambition and innovation \\
& $\begin{array}{l}\text { type (smooth/disruptive) to company ecosystem } \\
\text { R4 }\end{array}$
\end{tabular}




\begin{tabular}{|c|c|c|}
\hline & \multirow{3}{*}{\multicolumn{2}{|c|}{$\begin{array}{l}\text { works and delivers services in expected situations) } \\
\text { Other feasibility (economic: cost vs. perceived value, } \\
\text { competitiveness, societal acceptance, sustainable } \\
\text { properties, usage and perceptions, market launch } \\
\text { potential, etc.) } \\
\text { The chosen concept has a high potential for value } \\
\text { creation }\end{array}$}} \\
\hline R5 & & \\
\hline R6 & & \\
\hline 2) & \multicolumn{2}{|c|}{$\begin{array}{l}\text { A design process which is consciously driven by } \\
\text { value/utility probability and which is traceable } \\
\text { throughout the design process }\end{array}$} \\
\hline $\mathrm{R} 7$ & \multicolumn{2}{|c|}{ Intelligent problem (re-)setting } \\
\hline R8 & \multicolumn{2}{|c|}{ Sufficient exploration of briefs and concepts } \\
\hline R9 & \multicolumn{2}{|c|}{$\begin{array}{l}\text { Traceable problem solving process, identified decision } \\
\text { steps and clear decision alternatives }\end{array}$} \\
\hline $\mathrm{R} 10$ & \multicolumn{2}{|c|}{$\begin{array}{l}\text { Intermediary Design Objects are synthesized in books } \\
\text { that provide value }\end{array}$} \\
\hline R11 & \multicolumn{2}{|c|}{$\begin{array}{l}\text { The design process is traceable and thus may be } \\
\text { repeated in a slightly different context }\end{array}$} \\
\hline \multicolumn{3}{|c|}{ 3) Increase in knowledge and skills } \\
\hline $\mathrm{R} 12$ & \multirow{2}{*}{\multicolumn{2}{|c|}{$\begin{array}{l}\text { Consciousness of our innovations, values created and } \\
\text { differentiations } \\
\text { People have positively progressed into a shared } \\
\text { understanding of project stakes, results, design } \\
\text { methods and other people skills }\end{array}$}} \\
\hline $\mathrm{R} 13$ & & \\
\hline \multicolumn{3}{|c|}{ 4) Aggregate variables (summations) } \\
\hline $\mathrm{R} 14$ & (R14=R1:R13) & Overall value of the final result \\
\hline $\mathrm{R} 15$ & (R15=R1:R6) & $\begin{array}{l}\text { The chosen design concept is } \\
\text { innovative, mature and sufficiently } \\
\text { validated }\end{array}$ \\
\hline $\mathrm{R} 16$ & (R16=R7:R11) & $\begin{array}{l}\text { A design process that is } \\
\text { consciously driven by value/utility } \\
\text { probability, and it is traced }\end{array}$ \\
\hline $\mathrm{R} 17$ & (R17=R7:R13) & $\begin{array}{l}\text { Traced design process and clear } \\
\text { knowledge and skills acquisition }\end{array}$ \\
\hline
\end{tabular}

In addition to analyzing the presentations, three final evaluations were made by the 8 jury members. First, the design means were carefully examined and evaluated using 19 variables (see Table 1). For this purpose, a double evaluation was carried out by one experienced and one confirmed jury member. The same two jurists evaluated the 3 or 4 projects corresponding to the same subject. It should be noted that neither person had previously been a project expert. They were thus presumed to be novices on the innovation issue (project domain), but skilled in innovation management. Furthermore, these evaluation data were not averaged, so as to allow us to compare evaluation discrepancies between senior and junior experts.

Second, the project types were characterized by 9 variables (see Table 3) in terms of their subject (variable PID), nature of knowledge to explore (variables $\mathrm{K} 1$ to $\mathrm{K} 6$ ), the usage experience of the team members in design perimeter (variable
UK) and innovation type (more or less product or service, variable $\mathrm{P} / \mathrm{S}$ ). These evaluations were averaged for simplicity. Third, jury members were characterized by 2 variables (see Table 4) in terms of their seniority in design engineering and innovation management; this categorization was done both for evaluation of design results and evaluation of the design means.

Table 3. Main contextual variables. Scale: $-1=$ Not done; $0=$ Null; 1 = Insufficient; 2 = Average; 3 = Quite good; 4 = Good; $5=$ Very good

Design team features (through personal anonymous
questionnaires)

\begin{tabular}{|c|c|}
\hline $\mathrm{S} 1$ & Personal motivation (7-level scale) \\
\hline $\mathrm{S} 2$ & $\begin{array}{l}\text { Lively atmosphere perceived by design members (7- } \\
\text { level scale) }\end{array}$ \\
\hline $\mathrm{S} 3$ & $\begin{array}{l}\text { Presence rate at lecture sessions ( } \% \text { between } 0 \text { and } \\
100)\end{array}$ \\
\hline S4 & $\begin{array}{l}\text { Presence rate at tutorial sessions ( } \% \text { between } 0 \text { and } \\
100)\end{array}$ \\
\hline S5 & $\begin{array}{l}\text { Additional time spent on projects out of lecture and } \\
\text { tutorials (integer) }\end{array}$ \\
\hline S6 & Project team size (integer) \\
\hline S7 & Number of committed students (integer) \\
\hline S8 & $\begin{array}{l}\text { Degree of understanding of expected results and } \\
\text { deliverables (7-level scale) }\end{array}$ \\
\hline S9 & $\begin{array}{l}\text { Personal degree of satisfaction of the accomplished } \\
\text { work ( } 7 \text {-level scale) }\end{array}$ \\
\hline S10 & $\begin{array}{l}\text { Belief in the feasibility of the chosen design concept } \\
\text { (7-level scale) }\end{array}$ \\
\hline \multicolumn{2}{|r|}{$\begin{array}{l}\text { Project type features (averages from the jury member } \\
\text { assessments) }\end{array}$} \\
\hline PID & Project identifier (integer) \\
\hline 1. & Plastic bag facilitator \\
\hline 2. & Innovative carpool system/service \\
\hline 3. & CD_ROM storage \\
\hline 4. & Weighing machine adapted to African children \\
\hline 5. & Non-wood based African stove \\
\hline
\end{tabular}

Levels of skills/knowledge/investigation required to be productive (for all $K i$, scale from $1=$ not necessary to $5=$ fundamental)

\begin{tabular}{l|l} 
K1 & Engineering knowledge \\
K2 & Technological knowledge \\
K3 & Market knowledge \\
K4 & Societal knowledge \\
K5 & Usage knowledge \\
K6 & (K6=K1:K5) Overall amount of knowledge needed to \\
UK & $\begin{array}{l}\text { Use productive } \\
\text { perimeter } \\
\text { P/S }\end{array}$ \\
Percentage of Product vs. Service embedded in the
\end{tabular}


initial design statement (real between 0 and 1, 1 for a

pure product with no service part)

A total of 61 variables were directly evaluated. Subsequently, 6 new aggregate variables were generated from summations of assessed variables (e.g., means variables D20 and D21 (see Table 1), and results variables R14 to R17 (see Table 2)). Most of the aforementioned variables were assessed on a 7-level scale. The different contextual variables (Table 3) were measured using a 5-level scale, an integer or a percentage scale.

Concerning variable P/S (Product/Service), each jury member (an expert in innovation management) was asked to evaluate the topic of the initial design statement using a Product to Service orientation continuum (Fig. 9): where the variable has a value of 0 , it indicates that the topic is fully productoriented; if the variable is 1 , it is fully service-oriented. For example, project \#2 (Innovative carpool system/service) was determined to be more service-oriented. Other projects had a non-negligible service component; for instance, project \#1 (Plastic bag facilitator) could entertain a new way to shop as a potential solution.

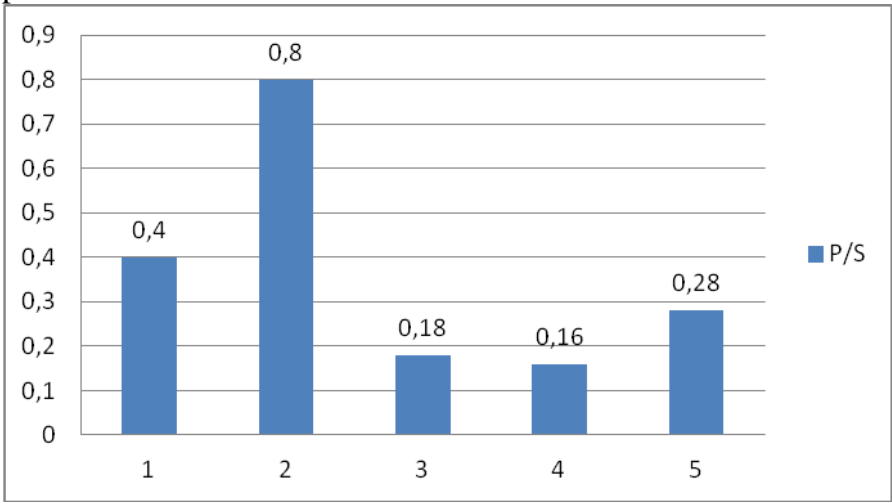

Fig. 9. Percentage of Product versus Service embedded in the initial design statement of the 5 projects: variable $\mathrm{P} / \mathrm{S}$

In addition, each jury member was asked to evaluate the types of skills or knowledge they assumed would be needed to properly set and investigate the problem, and then successfully develop solutions for it. Five types of knowledge - Engineering (K1), Technological (K2), Market (K3), Social (K4) and Usage (K5) - were evaluated using a 5-point scale where a value of "5" meant absolutely necessary knowledge. It should be noted that having proper definitions of the 5 natures of knowledge is not trivialized; on the contrary, definitions of the required knowledge were thoroughly discussed among all jury members before evaluations were completed. These evaluations are given in Fig. 10. It may be observed that projects demanded somewhat different prerequisite knowledge profiles from the students. Jury members observed that the acquisition of knowledge of usage contexts was fundamental in successful innovative product/solution generation projects.
Table 4: Secondary contextual variables

Jury members features

RV1 Jury member of the means (expert or confirmed)

RV2 Jury member of the results (expert or confirmed)

RID adoption: Have the objectives of the RID lecture been reached? (through personal anonymous questionnaires)

F1 How to start an innovation project?

F2 How to maximize design creativity?

F3 How to maximize value of an innovative project?

F4 How can each designer be a part of an innovative design team?

How to communicate in a design project with team

F5 members who do not have the same education (engineers, industrial designers, business students)? How to find a standard of communication, of

F6 action/roles, of project/task and knowledge management?

F7 How to do better than silo-innovations, not to work in

a client-supplier mode but to co-innovate?

F8 The problem setting stage has been well-achieved before starting the problem solving stage

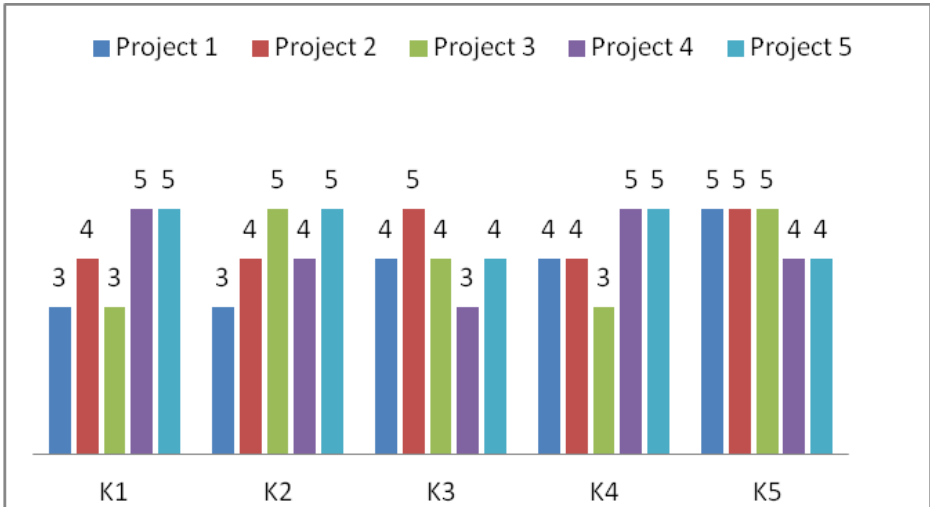

Fig. 10. Evaluation consensus reached considering the knowledge required for the realization of the project according to type of project

Given the sheer number of variables, it was thought necessary to have the big picture of the data collection intend, where all the variables are linked to relevant experimental setting actors or factors. This big picture was represented using Unified Modelling Language (UML), and is presented in Fig. 11. Different evaluation settings and jury members, as well as results, can be seen in this figure. We draw particular attention to the quality of innovativeness measures and aggregate values identified above: innovativeness, learning quality, final perceptions and process values. These aggregate variables represent the focus of our data analysis. 


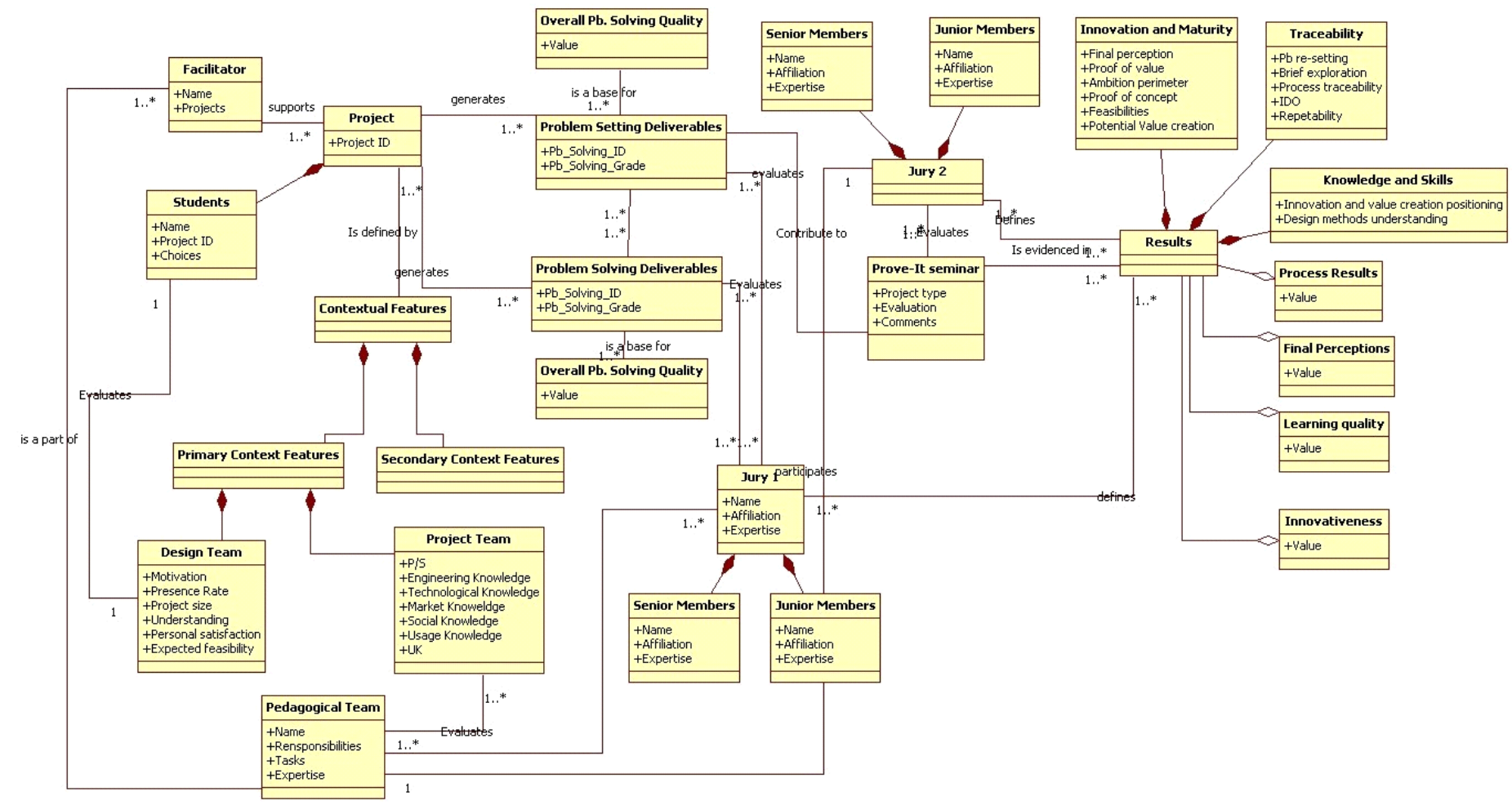

Fig. 11. UML model representing the data collection and RID experimental protocol

\section{ANALYSIS METHOD}

As previously mentioned, 19 design teams, their deliverables and their final design concepts were assessed through two reviews - the "Prove It" seminar and the examination of written reports - involving, respectively, four and two experts. This resulted in a sample of 152 data vectors. We included additional contextual variables related to the team members, project types and jury members to explore their possible influence on the quality of final results. These data vectors are not of the same size, since they refer to different objects; they include such factors as individual student, project team, project instance, project subject type, jury\#1 members, and jury\#2 members. We modelled the data to be processed by automatic Bayesian learning algorithms using the BayesiaLab software by building a unified aggregate data table corresponding to one student in one team working on one project type and assessed orally by four experts and by two others for the report. This operation resulted in a table of 696 vectors of size 67 , corresponding to the 61 observed and the 6 aggregate variables.

\subsection{Analysis method selection}

Given the categorical nature of some of our variables, the adoption of logistic regression might have been a natural choice to analyze the data to respond to the research questions presented in section 3. However, specific strengths of Bayesian Networks (BN) beyond standard logistic regression inspired us to choose $\mathrm{BN}$ as the modeling and analysis approach. First, the relationships across variables do not have to be prescribed using $\mathrm{BN}$; instead, the modeler can have the data speak to the existing relationships. For problem settings with as many variables as ours, this condition is advantageous. Second, although we have collected a sufficient level of observations/data to make generalizations, the capability of $\mathrm{BN}$ to integrate data uncertainty in structure modeling (Barton et al., 2008) [48] makes it easier to conduct what-if simulations to examine cases that are not observed. Temporal ordering of nodes in BN can support explorations with conjoint probability interpretations [49]. Finally, it should be mentioned that BN help avoid overfitting of data [50; 51], which might happen in regression applications [52].

Below we provide information on $\mathrm{BN}$ before discussing the analysis results.

\subsection{Bayesian Networks and variable relations discovery}

Bayesian Networks are directed acyclic graphs used to represent uncertain knowledge [53]. A BN is defined as a couple, $\mathrm{BN}=(\mathrm{S}, \mathrm{P})$, where $\mathrm{S}=(\mathrm{N}, \mathrm{A})$ represents the structure (i.e., the graph). "N" is a set of nodes. Each node represents a discrete variable $\mathrm{X}$ having a finite number of mutually exclusive states (modalities). Exclusive states can be considered as responses provided to a 7-point Likert scale, which we have used for some of our variables. "A" is a set of edges; the relation " $\mathrm{N} 1$ is a parent of $\mathrm{N} 2$ " is represented by an edge linking N1 to N2. In the case where N1 is an action or a state 
that temporally precedes N2, the edge may be interpreted as a causal relation.

$P$ represents a set of probability distributions associated with each node. When a node is a root node (it does not have a parent, i.e. edges pointing at this node), $\mathrm{P}$ corresponds to the probability distribution over the node states. When a node is not a root node, i.e. when it has some parent nodes pointing to it through directed edges, $\mathrm{P}$ corresponds to a conditional probability distribution that quantifies the probabilistic dependency between that node and its parents. It is represented by a Conditional Probability Table (CPT) governed by the Bayes theorem shown in equation (1). Experts based on their knowledge can define these conditional probability tables, but also one can use both parameter and structure learning algorithms in $\mathrm{BN}$ to define these parameters.

$$
P(A \| B)=\frac{P(B \| A) * P(A)}{P(B)}
$$

Most of the questions presented in section 3 can be seen as relationship discovery. BN accomplishes this in two ways: (1) constraint-based and (2) score-based. Constraint-based approaches use conditional independence assumption to discover relationships among variables (e.g., [54]). Score-based approaches define a scoring function to evaluate different candidate networks using the given data. Both approaches are based upon search algorithms identifying networks with a high score in a reasonable amount of time. These approaches are less dependent on data quality and have been implemented successfully in decision making [55].

We chose to use a score-based BN known as the Smart Greedy+ algorithm, originally proposed by Jouffe and Munteanu [56-58]. This hybrid algorithm consists of three steps: (1) a pre-processing algorithm, which involves collecting data on the best local network configuration for each node; this results in construction of the initial General Dependency network [59]; (2) a hybrid learning algorithm (Smart Greedy), which combines classical transformation operators of the scorebased algorithms with a novel heuristics for arc orientation and post-processing steps based upon constraint-based approaches; (3) a post-processing algorithm (Smart Greedy Order), that improves the final structure by realizing a restricted search in the space of topological order; for example, a node cannot appear before its parents. Experimental results show that this approach outperforms both Greedy and Tabu search algorithms [56-58], and hence is adopted here.

Overall, the use of $\mathrm{BN}$ in industry has increased in recent years, especially in risk management fields, marketing, and other domains where there is uncertainty and therefore a need to predict complex behavior, such as in a decision-making process. Recent examples in design engineering are also present (e.g., $[60 ; 61])$.

\subsection{Implementation details}

BayesiaLab software was used to implement the chosen analysis method. A unified aggregate data table corresponding to one student in one team working on one project type and assessed orally by four experts and by two others for the report was generated as the input to the algorithm. This operation resulted in a table of 696 vectors of size 67 , corresponding to the 61 observed and the 6 aggregate variables. In this operation, certain parts of some vectors were duplicated.

We began by building an unsupervised (that is, with no prescribed relationship) network from the entire dataset. Such an approach does not focus on predicting a particular targeted variable, but it does establish global probabilistic relationships among observed variables. The initial observation was performed through Maximum Weight Spanning Tree and the Minimum Description Length Score (see [62; 63] for a complete description). The use of a score-based approach rather than a constraint-based approach was motivated by the relatively small size of our dataset (700 data vectors). Ben Ahmed and Yannou [60] made the same choice (score-based approach) to generate more reliable results with a small number of samples.

We used the observation and analysis of log likelihood to assess the overall quality of unsupervised networks, and the accuracy and reliability of the different supervised networks we realized [64]. This measure compares the joint probabilities of the Bayesian network with the entire dataset.

The dataset used to build the network was subdivided into two subsets, learning and testing. A log likelihood density function was measured for each subset. If the measure tended towards $100 \%$, the joint probability of the whole dataset is entirely represented in the developed BN. For the case at hand, the two subsets, learning and testing, represented $80 \%$ and $20 \%$ of the data, respectively. The testing set was then used to validate relationships discovered in processing the learning set.

The performances of tested (semi-supervised or supervised) networks can also be assessed. Such an evaluation is performed through the analysis of many indicators such as a confusion matrix, a Gini index or a global accuracy index. The confusion matrix allows the observation of three things: the discrepancies between the predicted and real values for each modality of the supervised parameter; reliability (the ratio between predictions for a specific modality and the total number of predictions); and accuracy (the ratio between each prediction and the corresponding total of real values). A Gini index is measured for a specific targeted modality; it compares the detection rates of, respectively, a random value selection and a scheduled value selection. The higher the index value, the more reliable the model is.

For the collected data, the quality of the unsupervised $\mathrm{BN}$ was first calculated. The mean of log-likelihood for the two learning and testing subsets were, respectively, 77.18\% $(\mathrm{SD}=8.03 \%)$ and $79.09 \%(\mathrm{SD}=7.68 \%)$. Even if the size of the dataset was limited, these values are close enough to provide a good degree of fit for both subsets. Regarding semi-supervised D21, D20 and D9 networks, the global accuracy indicators we measured were $100 \%, 88.7 \%$ and $95.06 \%$, respectively. These observations indicate a high level of accuracy. Moreover, the 
reliability measured for each modality of the three semisupervised nodes varied from $85.37 \%$ to $100 \%$. The rate of good predictions for all three BN applications is therefore very high.

\section{RESULTS}

\subsection{Study of the overall quality of problem setting}

The analysis results presented in this section respond to Question 1 in section 3: What are the factors influencing the quality of the problem setting?

To gain information on D20 (overall quality of the problem setting phase) we used semi-supervised learning. This introduces an additional constraint in network building, requiring the identification of information specifically related to the D20 characterization. The resulting semi-supervised network (Fig. 12) shows the tight conditional probability of problem setting intensity (D20) with:

1) the overall quality of problem solving (variable D21) this is a strong relationship;

2) a proper redefinition of ideal need (variable D1); and

3) an extensive initial inventory of knowledge and competence needs (variable D4).

Fig. 13 shows the most dependent variables of D20 were D21, D1 and D4, which are directly linked to D20. The remaining 30 variables (of 63 total variables) that are included in the BN (in Fig. 12) are conditionally dependent on D21. In Fig. 12, the direction of the edges is not interpreted as a causal relationship; the indication is simply a notation convention to decide how to compute the Conditional Probability Table (CPT) linking two variables. Although the direction of the arrow may be inverted (the software allows this condition), the graph structure was not changed in accord with our decision not to prescribe relationships. However, one must also study indirect dependencies since strong dependencies can propagate throughout one or more nodes. Thus we also show dependency results of variables D3, D14, and K4, among others. Note that all the dependent variables studied in Table 5 appear framed by a dotted square in Fig. 12.

In Fig. 13, the presence and influence of all variables describing project type features can be observed: identifier (PID), ratio Product/Service (P/S), and different types of knowledge needed (K1 to K6); additionally, some of the design team features related to the effective commitment of students are evident (S4, S5, S6 and S7). One noticeable factor is the major influence of the numerous means in the success of the problem setting phase (D20), and the problem solving phase (D21). For instance, achieving a successful solving phase (D21) is positively influenced by:

- a good definition of usage contexts (D3), itself positively influenced by a proper definition of stakeholders (D2); and
- a good and productive organization of creativity (D9), itself positively influenced by a satisfactory production of books of knowledge (D5).

These last points confirm the importance of usage exploration and the continuous documentation of knowledge and the competences management throughout the design process.

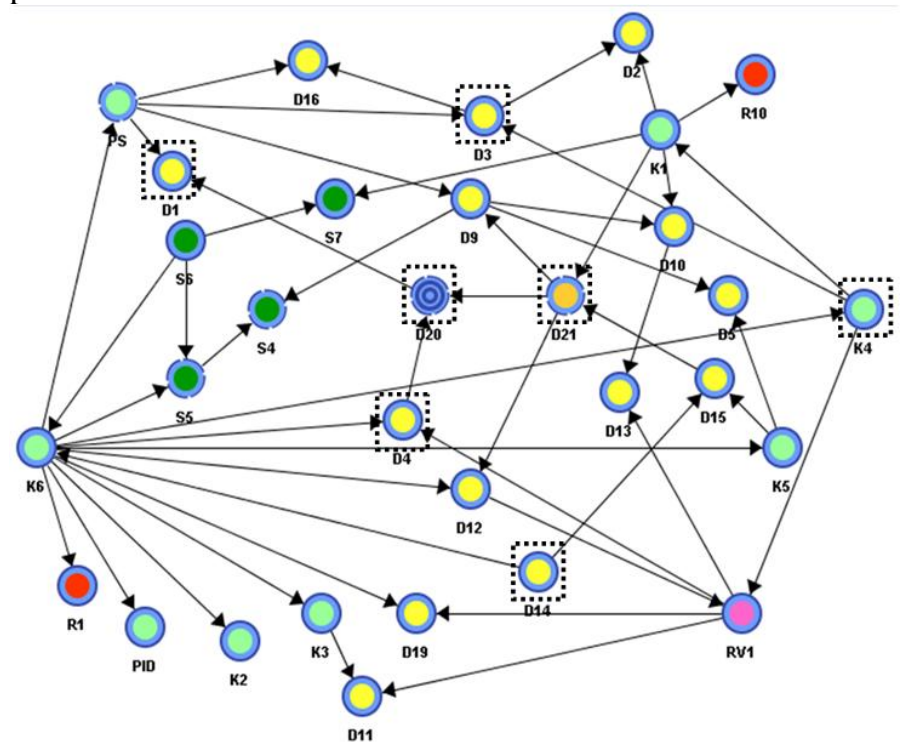

Fig. 12. Supervised network on D20 (overall quality of problem setting). (Green - design team features, Red - Results, Blue Project context, Yellow - Deliverables, Orange -Quality)

To explore in greater detail the relationships between different elements affecting the overall quality of problem setting, one can use this probabilistic inference model to predict model behavior, as depicted in Table 5. The objective is to explore the propagation of the information on D20 to the probability distributions of selected BN nodes, or "what if" scenarios. The initial distribution of variables learnt for the dataset is shown in Table 5 column (a). The other columns in Table 5 represent "what if" scenarios, changing the modality distribution of variable D20 to observe the variations in other variable distributions as compared to the initial distribution. The discrepancies with previous distributions are represented by arrows: green arrows for importantly increasing modality value, and red arrows for importantly decreasing modality value.

From Table 5, it can be observed that the more radical the redefinition of ideal need D1 (shift of D1 distribution toward higher values), the greater the value of D20. To achieve a problem setting D20 of good quality, variable D1 must range from good to excellent. The same phenomenon happens with variables D4 (initial inventory of knowledge and competence), D14 (concept sketching), K4 (social knowledge) and D21 (overall quality of problem solving). It might be seen as simply "expected" to find that D20 is dependent on D1 and D4 since D20 is defined as the sum of six terms which include D1 and D4. However, this is only partly true since results could have 
shown mutual opposite dependencies which cancel out. The mutual dependency between D20 and D21 is not trivial, or expected, and thus is further explained.

Table 5. Probabilistic "what if" inferences on D20 modalities. Column (a) represents initial distributions, the other columns represent "what if" scenarios starting from column (a) situation. "Moy" stands for "Mean" and "Ecart" for "Standard deviation"

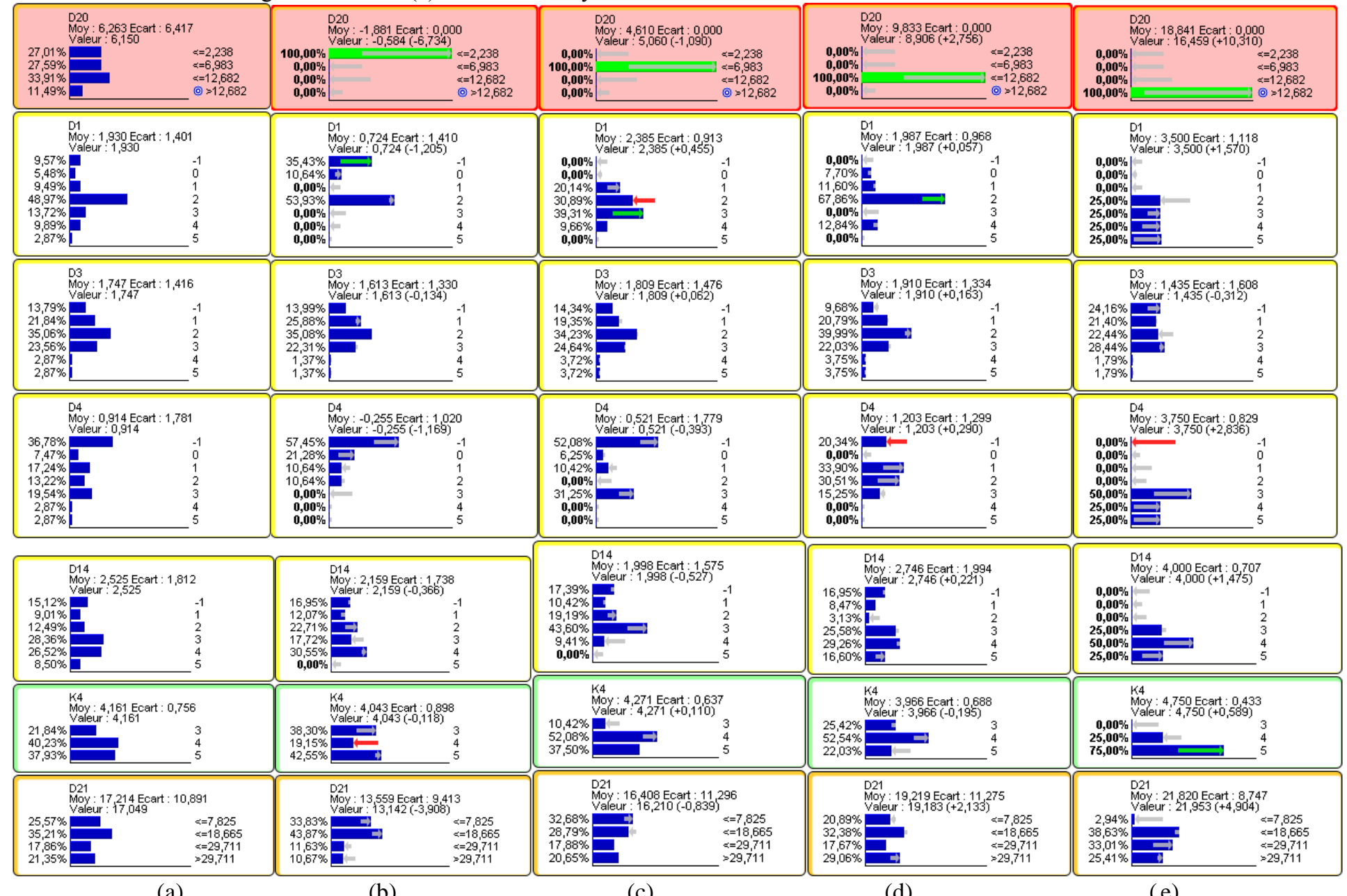

(a)

(b) (c)

observations the quality is barely satisfactory. Therefore, we can infer that when D1 is not realized, D20 is not good in $60 \%$ of observations, and there is a higher possibility that D21 will be of poor quality.

These observations particularly concern design projects in the field of product development (opposed to service), because $\mathrm{P} / \mathrm{S}=0$ in $100 \%$ of observations. More detailed observations show that service design projects in our context have produced a better definition of ideal needs, since the mean $\mu=2.922$ and standard deviation $\sigma=1.14$ for this variable increase. If $\mathrm{P} / \mathrm{S}<0.254$ (meaning that product design projects are more concerned), redefinition of ideal need D1 presents equal distribution, and initial inventory of knowledge and competence needs D4 is either not realized or of very poor quality in a majority of observations (D4 $<=0$ in $60 \%$ of observations). For $\mathrm{P} / \mathrm{S}$ in $] 0.2545,0.508]$, overall problem setting quality D20 increases (D20 $=2$ in $70.52 \%$ of observations) as well as initial inventories D4 (D4=1 in 38.70\%, D4=2 in $17.16 \%$ and D4=3 in 
$20.62 \%$ ). If $\mathrm{P} / \mathrm{S}$ is in $] 0.508,1]$, we observe a very small decrease in values of overall problem setting quality D20 and redefinition of ideal needs D1 increases in quality (D1=2 in $56.22 \%$ of observations, D1 $=3$ in $8.38 \%$ of observations, D1=4 in $22.4 \%$ and D1=5 in $13 \%$ ). Analyses show that the average for redefinition of ideal needs D1 increases from $\mu=0.36$ to $\mu=9.922$. It is interesting also to observe that initial inventory of knowledge and competence needs D4 has only two modalities: D4 $=-1$ in $74.04 \%$ and D4=3 in $28.96 \%$. This means that D4 in the majority of cases is not done, and when it is done, it is of quite good quality but lacks of maturity or completion.

\subsection{Study of the overall quality of problem solving}

In order to address Question 2 of our study, "What are the relations between problem setting efforts and the overall quality of the problem solving process?", we used semi-supervised learning on overall quality of problem setting D21. As in the previous section, we coupled the analyses of the structure of the learnt network with Bayesian inferences of the network.

A semi-supervised network on D21 (see Fig. 13) confirms the link between overall quality of problem setting D20 and overall quality of the problem solving D21, because D20 is one of the directly linked variables. Both supervised networks on D20 and D21 underline the importance of the problem setting phase in the overall radical design innovation process. The other directly linked variables which influence overall problem setting quality D21 are:

- a definition of present usage contexts (D3),

- a perceptual assessment of contexts (D12),

- $\quad$ a detailed concept (D15),

- $\quad$ efficient organization of creativity (D9), and

- $\quad$ required engineering knowledge (K1).

Moreover, we observe that the semi-supervised network also contains the majority of the design means in the problem setting phase (from D1 to D5).

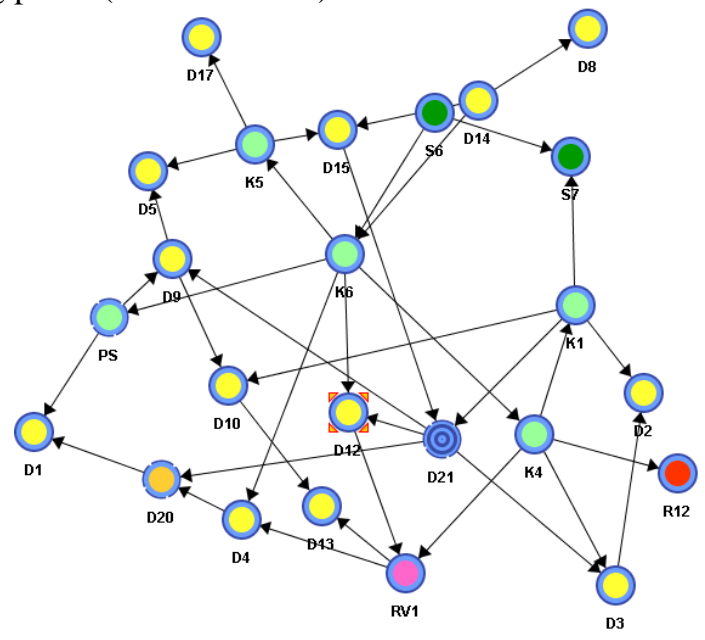

Fig. 13. Semi -supervised network on overall quality of problem solving D21

Given the variables present in the semi-supervised network, we explored the conditional probabilities between D21 and required engineering knowledge $\mathrm{K} 1$, definition of present usage contexts D3, perceptual assessment of contexts D12, detailed concept D15, organization of creativity D9 and overall quality of problem setting D20 (see Table 6). In addition, organization of the creativity process D9 (i.e., brainstorming workshops based upon the innovation leads), which appears to be influential, led us to analyze a semi-supervised network specific to D9.

The initial distribution of overall problem solving quality D21 ranges from 7.825 to 65 (recall that D21 is the summation of 13 variables whose value is in the range $\{-1,5\})$. D21 is evenly distributed among different modalities: D21<=7.825 in $25.96 \%$ of observations, D21 in $] 7.825,18.665]$ in $32.68 \%$ of observations, D21 in $] 18.665,29.711]$ in $20.22 \%$ of observations and D21 in ]29.771, 65] in $21.14 \%$ of observations. Overall quality of problem setting D20 ranges from $\mu=6.263$ and $\sigma=6.417$ to $\mu=3.726$ and $\sigma=5.134$. If the overall quality of the problem setting is poorly done, either unrealized or weak in most of the cases $\mathrm{D} 21<=7.825$, we observe that D20 is decreasing. We observe a decrease in two D20 modalities, D20 in ]2.238, 6.983] and D20 in >12.682 and increase of $\mathrm{D} 20<=2.238$. This means that if the overall quality of problem solving D21 is not realized, the probability is greater that overall problem setting quality D20 was either unrealized or weak. It can also be seen that detailed concepts are not done D15=-1 in $91.58 \%$ of observations.

As for the definition of present usage contexts, they are either unrealized (D3 $=-1$ in $29.31 \%$ ) or moderately done (D3=2 in $55.98 \%)$. The majority of these observations concern those projects that required a high level of engineering knowledge ( $\mathrm{K} 1=5$ in $64.80 \%$ ). As Table 6 shows, there is a dependency showing that to increase quality in the problem solving phase and innovation process, the problem setting phase needs to be of good quality. In particular, D3 (definition of present usage contexts), D12 (semantic differential profiles) and D15 (detailed concepts) from the problem solving phase must be done in a robust manner. The relation with D3 particularly confirms the belief among jury members of the importance of the knowledge of usage contexts. This is the only knowledge variable uniformly evaluated as necessary for each project type. 
Table 6. D21 impact modeling. Distribution of first level inference factors: K1, D3, D9, D12, D15, D20. "Moy" stands for "Mean" and "Ecart" for "Standard deviation"

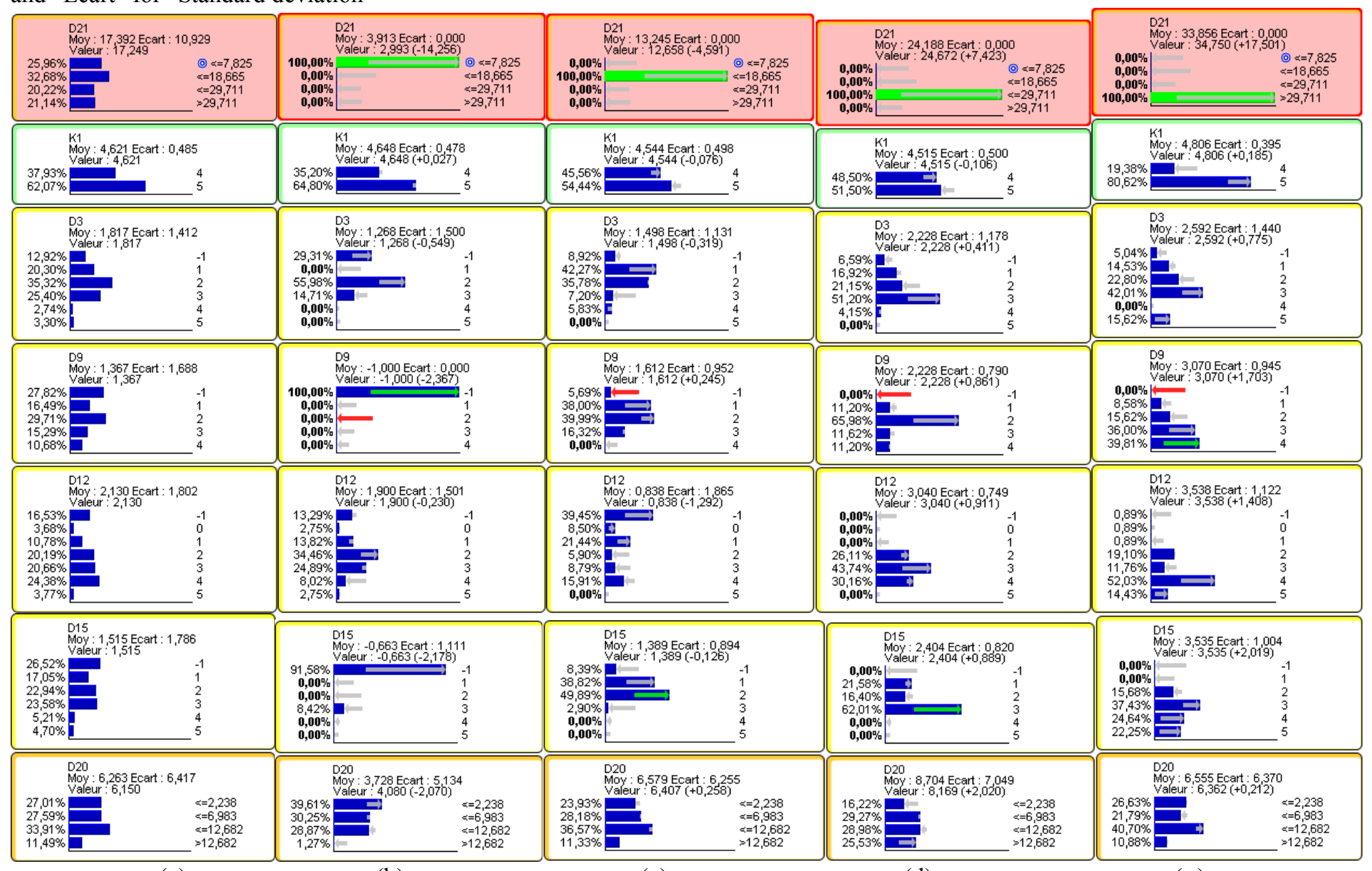

(a)

(b) (c) (d) (e)
When exploring the importance of different means in the problem solving phase, we observed some interesting behavior and the conditional probability between variable D9 and the overall quality of problem solving phase D21. It must be emphasized that means variable D9: organization of creativity is not only related to the successful achievement of brainstorming workshops; it is also the crystallization of the ideas condensed in knowledge books and identified innovation leads, defined in view of the definition of the global project context and presented usage contexts (see Fig. 14). The semi-supervised network on D9 in Fig. 14, aside from showing an interesting network complexity, also shows the impact of the project typology variables (Project ID number PID, required societal knowledge K4, Product or service $\mathrm{P} / \mathrm{S}$, required engineering knowledge $\mathrm{K} 1$ and Usage knowledge, i.e. required knowledge of use scenarios K5) on the quality of organization of creativity (D9) as well as on the overall quality of problem setting (D21). Moreover, overall quality of problem solving D21 is directly impacted by the means at the very beginning of the RID process, notably proper definition of the ideal needs, identification of stakeholders and adequate definition of the present usage context (D1, D2 and D3).

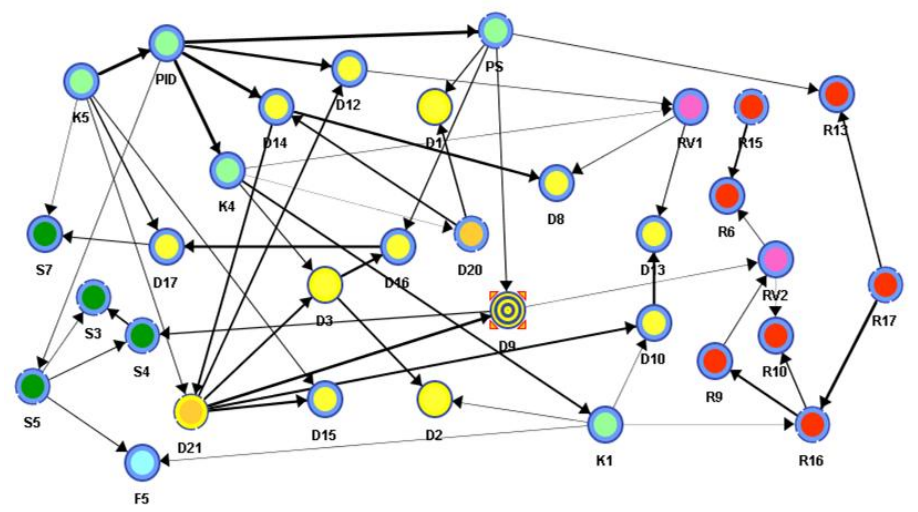

Fig. 14. Semi-supervised network concerning the Organization of creativity: brainstorming workshops based upon identified innovation leads D9

Finally, it can be observed that the overall problem solving quality D21 and organization of the creativity D9 are highly related. If overall problem solving quality is of relatively low 
quality $\mathrm{D} 21<=7.825$, the organization of creativity is not done D9 $=-1$ in $100 \%$ of cases. When D21 increases in quality (D21<= 18.665), the distribution of D9 also increases in quality (D9=1 in $38 \%, D 9=2$ in $39.99 \%$ and $\mathrm{D} 9=3$ in $16.32 \%$ of observations). This tendency is confirmed through D21 distribution. When D21>29.711 the quality of the mean variable D9 reaches much better evaluations (D9=4 in $39.81 \%$, D9 $=3$ in $36 \%$ and $\mathrm{D} 9=2$ in $16.62 \%$ ).

\section{DISCUSSION}

\subsection{Summary on the quality of the innovation process and importance of the design means}

After several simulations, the presented summary reflects the results from the BN shown in Fig. 15. The overall quality of problem setting process (D20) influences the overall quality of problem solving process (D21), through the quality of concept generation, here represented by the organization of creativity (D9). Main contextual factors that seem tightly related to the overall quality of the design process are the type of project (PID), the different types of required knowledge (K1, K4 and $\mathrm{K} 5)$, and the degree of product/service (P/S). We believe these factors should be analyzed beforehand to increase innovation likelihood, and therefore they should be integrated in design support and methods.

As a result of the simulations, evidence of the positive influence of three design means was ascertained in regard to the quality of the design process (both problem setting and problem solving). These design means are a proper definition of ideal needs (D1), a good identification of stakeholders (D2) and a good definition of present usage contexts (D3).

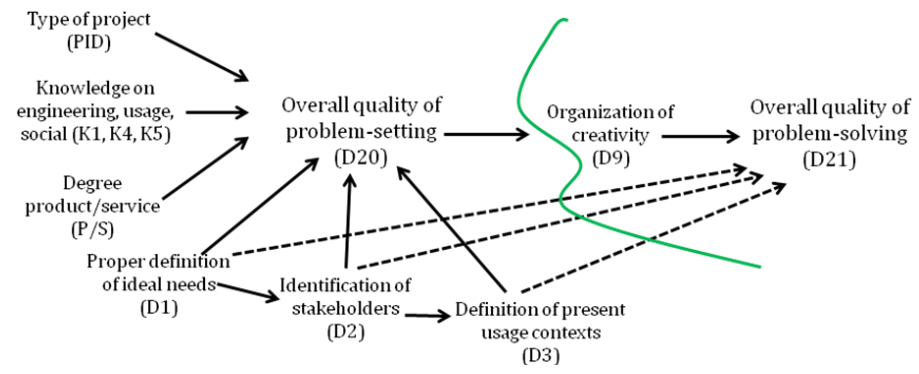

Fig. 15. A major finding of study: the overall quality of problem setting process dramatically influences the overall quality of problem solving process

\subsection{Evaluation of the perceived value of innovation projects}

To explore the value created during design processes and answer to Question 3 of our study, "Which relations exist between the apparent overall qualities of the problem setting and the problem solving process with the resulting quality or value of the innovative project outcome?", a network on R15 (innovation maturity and concept validation) was investigated (Fig. 16). One surprise in the resulting network is that there was no observed direct relationship between R15 and overall process qualities that introduced serious concerns in the data explorations. That is also the case with creativity (D9). This fact is confirmed by a "what-if" simulation of an increasing R15 value (see Table 7).

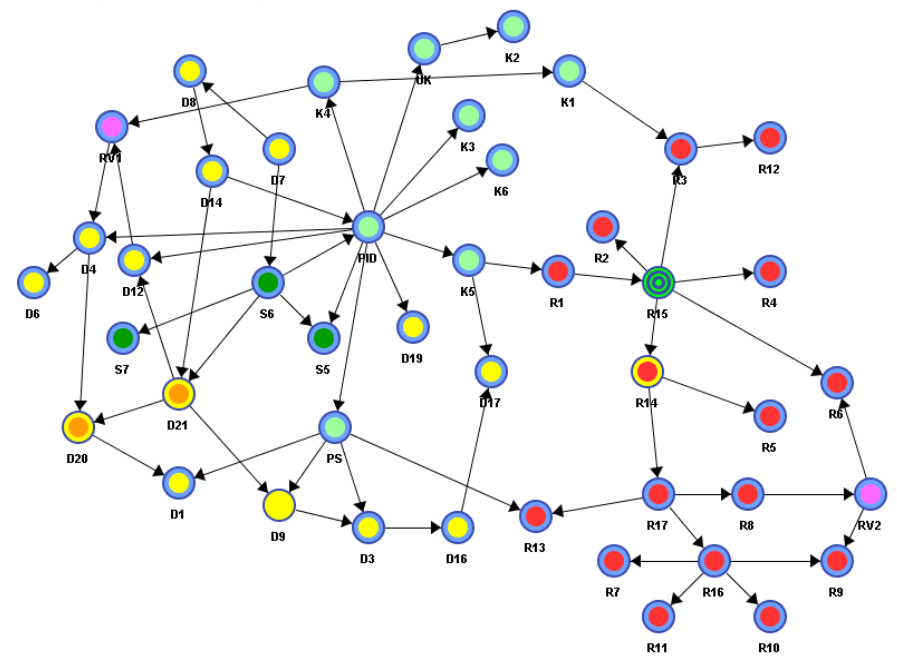

Fig. 16. Supervised learning on R15 "The chosen design concept is innovative, mature and sufficiently validated"

One possible conclusion is that one could afford not to care about the quality of the design process since the final value of the chosen design concept does not depend on it. We examined three possible hypotheses:

1. The RID innovation process is not insightful for resulting in a high value design solution for companies.

2. The jury members could have had trouble in assessing the maturity of "R" (design results) variables as well as difficulties in interpreting their meaning and their value.

3. The jury members were misled by the apparent value of the final chosen design concept during the fast oral presentation of the project outcomes.

Hypothesis \#1 was refuted since RID methodology prompts an intense and complete problem setting, and problem setting positively influences the creativity production (as documented in the existing literature), which in turn influences the quality of problem solving. Moreover, additional discussions were held with industry partners who were interested in values of chosen project concepts.

Hypothesis \#2 was refuted after interviewing the jury members.

Finally, after discussions with a jury member and an examination of the evaluations of both deliverables and results, we concluded the third hypothesis was the most likely. Let us recall that project presentations were made in company-like conditions, i.e. with no preexisting knowledge of the produced results. Several relevant points support this third hypothesis:

1. The level of expertise of the jury members during the oral examination (RV2, see Fig. 16 on the right) influenced the perception of the potential of value creation of the chosen design solution within the company ecosystem (R6), as well as the understanding that the briefs and design 
concepts were sufficiently explored (R8). Both variables R6 and R8 directly influenced the innovative project value outcomes R14 and R15. After verifications, the expert jury members clearly required a higher design process quality (D20 and D21) than the confirmed members for the weak projects.

2. Two tendencies observed in the weak project teams are that: (a) they were aware of their weaknesses and invested more in a flashy presentation, and (b) they had more time to prepare the presentation in contrast to the "serious

Table 7. R15 impact modeling. Distribution variables: R14, D20 and D9. "Moy" stands for "Mean" and "Ecart" for "Standard deviation"

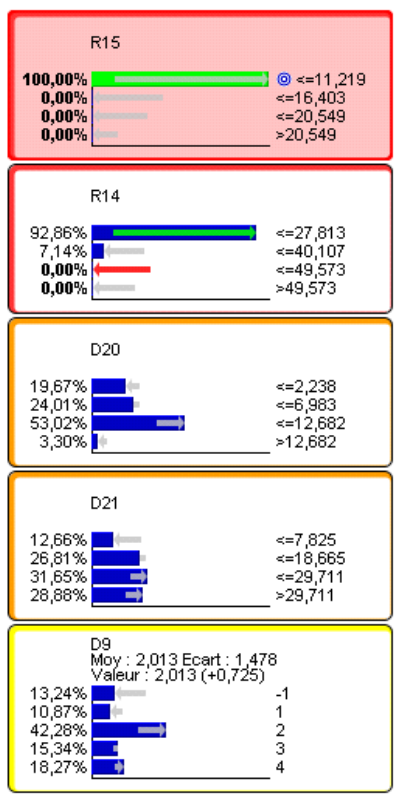

(a)

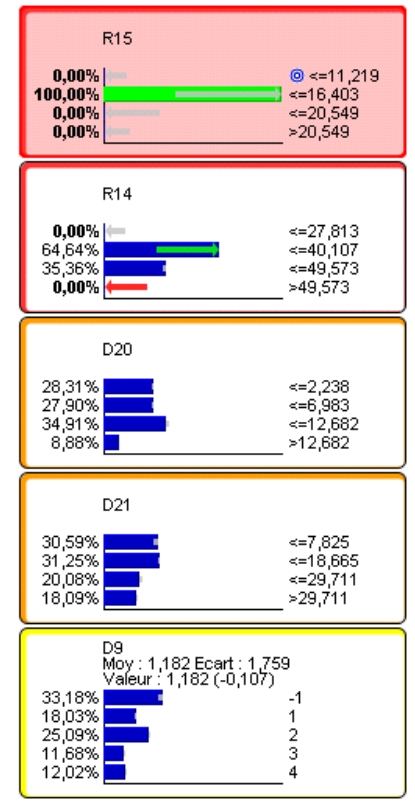

(b)

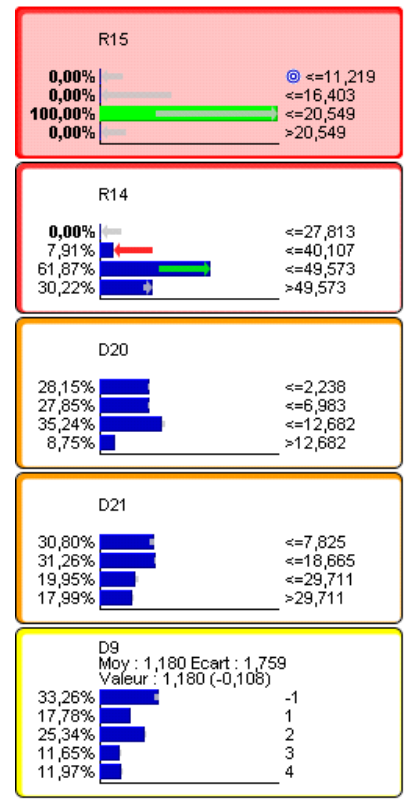

(c)

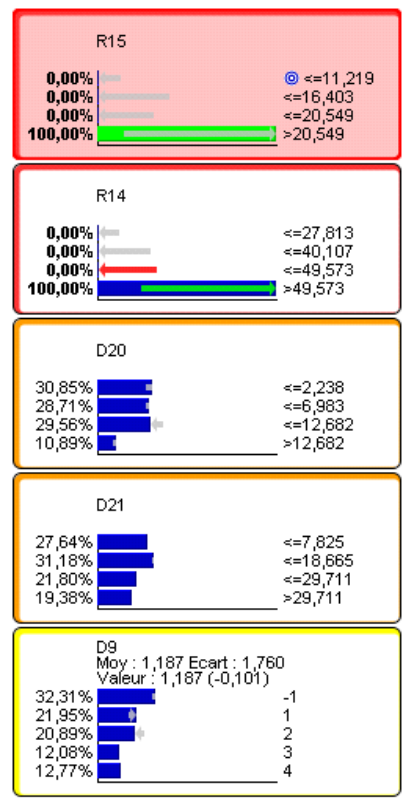

(d)
These explorations add more precaution concerning innovation evaluation. It seems that, echoing typical industry settings, innovation itself is very difficult to evaluate if all related points are not explored and verified. In our experience, a large percentage of innovation evaluation is done through "flash" presentation, and we believe this risk should be taken into account by potential investors. Thus, let us mention the importance of other elements such as the books of knowledge (e.g., books of patents, surveys of technologies, competing product literature) as well as the traceability or rationale (see $[65 ; 66])$ of the briefs and concepts explorations and of the associated decisions.

Finally, this analysis made us conscious of the discrepancies between the perceived values of an innovative project after a design review and the deep analysis of what has been called design means, including intermediate results generated along the innovative design process. Both evaluations have their own advantages. An oral and brief presentation has the advantage of summarizing the salient aspects of the resulting design concept and, based on immediate response, revealing if it may be convincing to customers. This aspect is teams" who invested more in the knowledge books and the required written reports containing the traceability elements of the design process.

3. Additional tendencies among "serious teams" show that: (a) they had less time to prepare the oral presentation - the projects were very constrained time-wise, and (b) they were more confident than the weak teams that jury would acknowledge their good work. the one emphasized by the Design Thinking approach. Complementarily, a later analysis of design means (rationale or Intermediate Design Objects generated along the design process) is necessary to bring proofs of concept and proofs of value of the design concept into the perspective of a coming product development and launch. Consequently, in view of discovered risks, we believe that there is a need to propose new innovation evaluation approaches in order to address this issue.

\section{CONCLUSIONS}

Much of the existing literature in design engineering considers creativity management or idea generation as starting from a well-stated customer need and design issue. In actual industry practice, however, companies face fuzzy front-end situations (see [2-4]) where the design problem remains to be set in terms of need justification and market profitability. To address this, we defined and proposed a methodological support for use during the problem setting state to identify needs and market opportunities. Henceforth, we propose to enlarge the concept of evaluation integrating industry ecosystem context (see Fig. 7). 
Factors which influence innovation outcomes were evaluated using RID as the design process model. These were tested in a large-scale experiment involving student design projects with the aim of replicating existing industry innovation evaluation and selection conditions as closely as possible. We proposed an evaluation protocol of innovative projects in two stages: a primary rapid oral presentation of the salient aspects of the innovation project and outcomes (design review as it could be in companies), and a secondary analysis of the design means (stages, intermediate results, and knowledge generated along the design process). We have also proposed three variable models to assess the innovation process: a model of design means variables (see Table 1), a model of design results variables (see Table 2) and a model of contextual variables (see Tables 3 and 4) including the type of project, the jury members, the design team initial skills and motivations. A Bayesian Network approach was used to explore the data. Several simulations were developed to analyze the propagations within the network structure and the change in conditional probability distributions.

The first finding is that radical innovation of the quality of the problem setting stage is a significant determinant; critical elements are a proper definition of ideal needs - what people fundamentally need or expect - an extensive knowledge of usage practices in the neighborhoods of the initial idea, and a real knowledge of stakeholders of existing product-service value chains. This finding contradicts the Design Thinking attitude of "Do it as soon as possible and improve it if necessary," suggesting a more business intelligence attitude of "Explore the available information before digging in one precise direction".

A second major finding is that the importance of design context, including the company ecosystem, the type of subject product versus service, unusual knowledge for the company the team skills and motivations - cannot be understated. Analyses show that such variables influence the innovation process and modulate effects, often with conditional or nonlinear effects, which justify a posteriori the choice of Bayesian Networks for learning and simulation. For example, engineering knowledge and usage knowledge are significant success factors for certain types of need-driven radical innovations. For these innovations, one should address these issues rather than expecting too much from creativity workshops. It also means that an innovation process cannot be driven by a rigid prescriptive methodology imposing a fixed stage-and-gate process. This is why we believe now more in an agile innovation process that must be consciously adapted beforehand after an analysis of the innovation stakes of a particular project. Our future research will be directed towards this question.

In the end, our analyses underline the necessity to be cautious in assessment of idea quality or innovative projects. Few existing papers consider the experience of people performing innovation appraisals. We discovered that the traditional fast design reviews to make decisions at the end of an innovation project - or a conceptual design stage - could be counter-productive, since several rebound-effects can explain that "flashy" presentations of a chosen design concept of medium quality can be preferred to more apparently dull justifications of a good problem setting and an exhaustive brief and concept exploration - good problem solving. However, our experiments clearly show that a good problem solving process depends on a good problem setting process; and that these design process assessments must be done carefully by screening appropriate design documents. This consideration on how to proceed for a design evaluation to make the decision of developing or not a chosen design concept is also of major importance. We believe this issue should be addressed further to establish a holistic approach to innovation selection.

\section{REFERENCES}

[1] Shah J.J., Kulkarni S.V., Vargas-Hernandez N., 2000, "Evaluation of Idea Generation Methods for Conceptual Design: Effectiveness Metrics and Design of Experiments", Journal of Mechanical Design, 122, No. 4, pp. 377-385.

[2] Motte D., Bjärnemo R., Yannou B., 2011, "On the interaction between the engineering design and development process models - Part I: Elaborate Elaborations on the generally accepted process models", Proc. ICoRD: 3rd International Conference on Research into Design, January 10-12, Bangalore, India.

[3] Motte D., Bjärnemo R., Yannou B., 2011, "On the interaction between the engineering design and the development process models - Part II: Shortcomings and limitations", Proc. ICoRD: 3rd International Conference on Research into Design, January 10-12, Bangalore, India.

[4] Motte D., Yannou B., Bjärnemo R., 2011, "The specificities of radical innovation", Proc. ICoRD: 3rd International Conference on Research into Design, January 10-12, Bangalore, India.

[5] Pahl B., Beitz W., 1996 Engineering Design: A Systematic Approach, Springer, Technology \& Industrial Arts, ISBN 3540199179.

[6] Ulrich K.T., Eppinger S.D., 1995, Product Design and Development, McGraw-Hill, New York.

[7] Cross N., 1994, Engineering Design Methods - Strategies for product design, John Wiley \& Sons, Chichester.

[8] Liu Y.C., Chakrabarti A., Bligh T., 2003, "Towards and 'ideal' approach for concept generation", Design Studies, 24, No. 4, pp. 341-355.

[9] Pugh S., 1990, Total Design: Integrated methods for successful product engineers, Addison Wesley, New-York.

[10] Lawson B., 2006, How Designers Think: The Design Process Demystified, Architectural Press, Oxford. 
[11] Portillo M., 2009, Color planning for interiors: an integrated approach to color in designed spaces, Wiley \& Sons.

[12] Portillo M., Dohr J.H., 1994, "Bridging process and structure through criteria", Design Studies, 15, No. 4, pp. 403-416.

[13] Gann D., Salter A., Whyte J., 2003, "Design Quality Indicators as a tool for thinking", Building Research \& Information, 31, No. 5, pp. 318-333.

[14] Jones E., Stanton N.A., Harrison D., 2001, "Applying structured methods to Ecoinnovation. An evaluation of the Product Ideas Tree diagram", Design Studies, 22, No. 6, pp. 519-542.

[15] Pinch S., Sunley P., Macmillen J., 2010, "Cognitive mapping of creative practice: A case study of three English design agencies", Geoforum, 41, pp. 377-387.

[16] Shah J., Vargas-Hernandez N., 2003, "Metrics for measuring ideation effectiveness", Design Studies, 24, No. 2, pp. 111-134.

[17] Astebro T., 2004, "Key Success Factors for Technological Enterpreneurs' R\&D Projects", IEEE Transactions on Engineering Management, 51, No. 3, pp. 314-321.

[18] Millier P., 1999, Marketing The Unknown: Developing Market Strategies For Technical Innovations, John Wiley\&sons, New-York.

[19] Dong A., Hill A.W., Agogino A., 2004, "A Document Analysis Method for Characterizing Design Team Performance", Journal of Mechanical Design, 126, pp. 378-385.

[20] Yang M., 2004, "An examination of prototyping and design outcome", Proc. ASME Design Engineering Technical Conferences, Salt Lake City, USA.

[21] Yang M., 2009, "Observations on concept generation and sketching in engineering design", Research in Engineering Design, 20, No. 1, pp. 1-11.

[22] Yang M.C., 2003, "Concept generation and sketching: Correlations with design outcome", Proc. DETC-DTM: ASME Design Engineering Technical Conferences Design Theories and Methodologies, September 2-6, Chicago, Illinois, USA.

[23] Gero J.S., Kazakov V., 1996, "An exploration based evolutionary model of a generative design process", Microcomputers in Civil Engineering, 11, pp. 209-216.

[24] Roozenburg N.F., Eekels J., 1995, Product Design: Fundamentals and Methods, John Wiley \& Sons, Chichester.

[25] Fricke G., 1996, "Successful individual approaches in engineering design", Research in Engineering Design, 8, pp. 151-156.
[26] Sarkar P., Chakrabarti A., 2007, "Understanding Search in Design", Proc. International Conference on Engineering Design (ICED07), August, Paris, France.

[27] Römer A., Leinert S., Sachse P., 2000, "External support of problem analysis in design problem solving", Research in Engineering Design, 12, No. 3, pp. 144-151.

[28] Tovey M., Porter S., Newman R., 2003, "Sketching, concept development and automotive design", Design Studies, 24, No. 2, pp. 135-153.

[29] Yang M., Cham J., 2007, "An Analysis of Sketching Skill and Its Role in Early Stage Engineering Design", Journal of Mechanical Design, 129.

[30] Mabogunje A., Leifer L., 1996, "Measuring the Mechanical Engineering Design Process", Proc. 26th Annual Frontiers in Education Conference on Technology-Based Re-Engineering Engineering Education, Salt Lake City, USA.

[31] Yang M.C., Wood W.H., Cutkosky R., 2005, "Design information retrieval: a thesauri-based approach for reuse of informal design information", Engineering with Computers, 21, pp. 177-192.

[32] Kulkarni S., 1998, "Idea Generation Techniques-a critical survey", Arizona State University.

[33] VanGundy A.B., 1988, (2nd Ed.) Techniques of Structured Problem Solving, Van Nostrand Reinhold, New York.

[34] Chakrabarti A., 2009, "Design Creativity Research", in Product Research: The Art and Science Behinf Sucessful Product Launches, Springer Science+Business Media B. V., Vol. DOI 10.1007/978-90-481-2860-0.2, pp. 17-39.

[35] Davis G.A., 1999, Creativity is Forever, 4th Edition ed, Kendall Hunt, Dubuque Iowa.

[36] Fox J.M., Fox R.L., 2000, Exploring the Nature of Creativity, Kendal Hunt, Dubuque Iowa.

[37] Gluck F.W., 1985, "'Big Bang" Management", Journal of Business Strategy, 6, No. 1, pp. 59-64.

[38] McKim R.H., 1980, Thinking visually: A strategy manual for problem solving, Lifetime Learning Publications Belmont, CA.

[39] Sarkar P., Chakrabarti A., 2011, "Assessing design creativity", Design Studies, 32, No. 4, pp. 348-383.

[40] Chakrabarti A., Sarkar P., Leelavathamma B., Nataraju B.S., 2005, "A Functional Representation for Aiding Biomimetic and Artificial Inspiration of New Ideas", $A I$ EDAM, 19, No. 2, pp. 113-132.

[41] Srinivasan V., Chakrabarti A., 2008, "Design for Novelty A Framework?", Proc. Design Conference, May 19-22, Dubrovnik, pp. 237-244. 
[42] Goldschmidt G., Tatsa D., 2005, "How good are good ideas? Correlates of design creativity", Design Studies, 26, No. 6, pp. 593-611.

[43] Goldschmidt G., 1990, "Linkography: assessing design productivity", Proc. Tenth European Meeting on Cybernetics and Systems Research, Singapore, R Trappl.

[44] Goldschmidt G., 2003, "Cognitive economy in design reasoning", in Human behaviour in design : individuals, teams, tools, Lindeman U. Editor, Springer Verlag, Berlin, pp. 53-62.

[45] van der Lugt R., 2001, "Sketching in design idea generation meetings", PhD Dissertation, Faculty of Industrial Design, Delft University of Technology.

[46] Rianantsoa N., Yannou B., Redon R., 2010, "Concept-tovalue: Method and tool for value creation in conceptual design", Proc. IDETC/DAC: ASME International Design Engineering Technical Conferences \& Computers and Information in Engineering Conferences / Design Automation Conference, August 15-18, Montreal, Canada.

[47] Rianantsoa N., Yannou B., Redon R., 2010, "Dynamics of definition and evaluation of value creation strategies and design concepts", Proc. IDMME Virtual Concept, October 20-22, Bordeaux, France.

[48] Barton D.N., Saloranta T., Moe S.J., Eggestad H.O., Kuikka S., 2008, "Bayesian belief networks as a metamodelling tool in integrated river basin management - Pros and cons in evaluating nutrient abatement decisions under uncertainty in a Norwegian river basin", Ecological Economics, 66, No. 1, pp. 91-104.

[49] Jensen F.V., Nielsen T.D., 2007, Bayesian networks and decision graphs, New York: Springer Science+Business Media, LLC, New York.

[50] Chan Z.S.H., Ngan H.W., Rad A.B., David A.K., Kasabov N., 2006, "Short-term ANN load forecasting from limited data using generalization learning strategies", Neurocomputing, 70, No. 1-3, pp. 409-419.

[51] Saini L.M., 2008, "Peak load forecasting using Bayesian regularization, Resilient and adaptive backpropagation learning based artificial neural networks", Electric Power Systems Research, 78, No. 7, pp. 1302-1310.

[52] Grünwald P.D., 2007, The Minimum Description Length Principle, The MIT Press, ISBN-10:0-262-07281-5, NewYork.

[53] Jensen F.V., 1996, An Introduction to Bayesian Networks, UCL Press, London.

[54] Spirtes P., Glymour C., Scheines R., 2000, Causation, Prediction, and Search, MIT Press, 2nd edition, Cambridge, MA.
[55] Heckerman D., Geiger D., Chickering D.M., 1995, "Learning Bayesian networks: the combination of knowledge and statistical data", Machine Learning, 20, No. 3, pp. 197-243.

[56] Jouffe L., 2002, "Nouvelle classe de méthodes d'apprentissage de réseaux bayésiens", Proc. Journées francophones d'Extraction et de Gestion des Connaissances (EGC), Montpellier, France.

[57] Jouffe L., Munteanu P., "Smart-Greedy+ : Apprentissage hybride de réseaux bayésiens", in Colloque francophone sur l'apprentissage (CAP), Saint Etienne, France, 2000.

[58] Munteanu P., Bendou M., 2001, "The EQ Framework for Learning Equivalence Classes of Bayesian Networks", Proc. First IEEE International Conference on Data Mining (IEEE ICDM), San José, pp. 417-424.

[59] Heckerman D., Meek C., Cooper G., 1999, "A Bayesian approach to causal discovery", in Computation, Causation, and Discovery, Glymour C. , Cooper G. Editors, MIT Press, Cambridge, pp. 141-165.

[60] Ben Ahmed W., Yannou B., 2009, "A bayesian learning of probabilistic relations between perceptual attributes and technical characteristics of car dashboards to construct a perceptual evaluation model", International Journal of Product Development, special Issue on "Engineering Emotional Design (EED) and Kansei Engineering (KE)", 7, No. 1-2, pp. 47-72, DOI: 10.1504/IJPD.2009.022276.

[61] Cai Z., Sun S., Si S., Yannou B., 2011, "Identifying product failure rate based on a conditional Bayesian network classifier", Expert systems with applications, 38, No. 5, May 2011 (DOI: 10.1016/j.eswa.2010.09.146), pp. 5036-5043.

[62] Bouckaert R.R., 1993, "Probabilistic network construction using the minimum description length principle", Lecture notes in computer science, 747, pp. 41-51.

[63] Lam W., Bacchus F., 1994, "Learning bayesian belief networks: An approach based on the MDL principle", Computational Intelligence, 10, pp. 269-293.

[64] BayesiaLab, "Bayesia tutorial Book", 2006, pp. available on www.bayesialab.com.

[65] Aurisicchio M., Gourtovaia M., Bracewell R., Wallace K., 2008, "How to evaluate reading and interpretation of differently structured engineering design rationales", Artificial Intelligence for Engineering Design, Analysis and Manufacturing, 22, pp. 345-358.

[66] Bracewell R., Wallace K., Moss M., Knott D., 2009, "Capturing design rationale", Computer-Aided Design, 41, pp. 173-186. 